\title{
CXCR3 signaling in glial cells ameliorates experimental autoimmune encephalomyelitis by restraining the generation of a pro-Th17 cytokine milieu and reducing CNS-infiltrating Th17 cells
}

\author{
Chen-Yen Chung and Fang Liao*
}

\begin{abstract}
Background: Experimental autoimmune encephalomyelitis (EAE) is a mouse model of multiple sclerosis (MS). It has been shown that Th17 cells are critical for EAE pathogenesis. Mice lacking CXCR3 develop aggravated EAE compared with wild-type (WT) mice. This study investigated the effect of CXCR3 on Th17 expansion during EAE and further addressed the underlying mechanism.
\end{abstract}

Methods: Both active EAE and adoptive-transfer EAE experiments were employed for studying EAE pathogenesis in $W T$ and $\mathrm{CXCR3}^{-1-}$ mice. Demyelination and leukocyte infiltration in the spinal cord of mice were analyzed by luxol fast blue staining and flow cytometry analysis, respectively. Glial cells expressing CXCR3 in the spinal cord were analyzed by immunofluorescence staining. Cytokine and chemokine levels in the spinal cord were analyzed using quantitative real-time PCR and enzyme-linked immunosorbent assay (ELISA). The glial cell line U87MG was employed for studying the CXCR3 signaling-mediated mechanism regulating Th17 expansion.

Results: $\mathrm{CXCR3}^{-/-}$mice exhibited more severe EAE and had significantly increased central nervous system (CNS)infiltrating Th17 cells compared with WT mice. Adoptive-transfer experiments showed that $\mathrm{CXCR}^{-1-}$ recipient mice that received Th17 cells polarized from splenocytes of myelin oligodendrocyte glycoprotein (MOG)-immunized $\mathrm{CXCR3}^{-1-}$ mice or MOG-immunized WT mice always developed more severe EAE and had significantly increased CNS-infiltrating Th17 cells compared with WT recipient mice that received Th17 cells from the same origin. Furthermore, during EAE, the number of activated glial cells was increased in the CNS of MOG-immunized $\mathrm{CXCR3}^{-1-}$ mice, and CXCR3-deficient glial cells expressed increased levels of cytokine genes required for Th17 expansion and recruitment. Finally, we found that extracellular signal-regulated kinase (ERK) activation elicited by CXCR3 signaling in U87MG cells attenuated the activation of NF-KB, a key transcription factor critical for the induction of IL-23 and CCL20, which are required for Th17 cell expansion and recruitment, respectively.

Conclusions: This study demonstrates a previously unrecognized role of CXCR3 signaling in glial cells in negatively regulating Th17 cell expansion during EAE. Our results demonstrate that, in addition to its well-known role in the recruitment of immune cells, CXCR3 in CNS glial cells plays a critical role in restraining the pro-Th17 cytokine/ chemokine milieu during EAE, thereby diminishing Th17 cell expansion in the CNS and suppressing disease development.

Keywords: CXCR3, Experimental autoimmune encephalomyelitis, Th17, Glial cells

\footnotetext{
* Correspondence: fl9z@ibms.sinica.edu.tw

Institute of Biomedical Sciences, Academia Sinica, Taipei 11529, Taiwan
} 


\section{Background}

Multiple sclerosis (MS) is a chronic demyelinating inflammatory disease of the central nervous system (CNS) that leads to neurological impairment and, subsequently, disability in the majority of patients [1]. A mouse model of MS is the experimental autoimmune encephalomyelitis (EAE) [2]. The pathogenesis of MS and EAE results from infiltration of the CNS by myelin-specific autoreactive $\mathrm{T}$ cells, which attack the myelin sheath. The Th1 subset of T cells, driven by stimulation with interleukin12 (IL-12), composed of p40 and p35 subunits, has traditionally been considered essential for the pathogenesis of EAE because mice lacking the p40 subunit are resistant to EAE [3, 4]. However, in contrast to mice lacking the p40 subunit, mice lacking the p35 subunit are highly susceptible to the induction of EAE, establishing that IL12 p70 may not be essential for the development of EAE [5]. Notably, the p40 subunit of IL-12 is shared by IL-23, composed of p40 and p19 subunits [6], and mice lacking either of these subunits are resistant to EAE [7], suggesting that IL-23 is central to the development of EAE. Because IL-23 is critical for the maintenance, survival, and proliferation of Th17 cells $[8,9]$, this T cell subtype has since been thought to play a pivotal role in the development of EAE. Consistent with this idea, mice lacking IL17 or ROR $\gamma$ t, a transcription factor for Th17 cells, and mice treated with an IL-17 blocking antibody are less susceptible to EAE [9-11]. Importantly, autoreactive Th17 cells preferentially expressing CCR6 have been shown to trigger the initial inflammation by entering the CNS through the choroid plexus via a CCR6-CCL20dependent mechanism and further infiltrating the CNS parenchyma by a CCR6-independent mechanism [12]. In accord with these findings, studies in human patients have shown that Th17 cells are involved in MS $[13,14]$.

The $\mathrm{C}-\mathrm{X}-\mathrm{C}$ motif chemokine receptor CXCR3 is mainly expressed on effector leukocytes, including $\mathrm{CD} 4^{+}$and CD8 ${ }^{+}$T cells, natural killer (NK) cells, NKT cells, and subsets of B cells [15]. CXCR3 and its ligands, CXCL9, CXCL10, and CXCL11, play a pivotal role in the regulation of inflammatory and infectious diseases, in which CXCR3-bearing effector leukocytes are recruited to the sites of inflammation or infection [16]. In particular, CXCR3 and its ligands play crucial roles in mediating inflammatory diseases of the CNS $[17,18]$ and in controlling neurotropic viral infection in the CNS [19-24]. Although CXCR3 is mainly expressed on cells of hematopoietic origin, CXCR3 and its ligands have been detected in the CNS [25-28]. Thus, it is expected that CXCR3 and its ligands would not only be critical for the recruitment of effector leukocytes but could also be important for the regulation of CNS physiology during CNS inflammation and infection.

Interestingly, studies on the role of CXCR3 in EAE have yielded quite controversial findings [29-31]. Two reports have shown that $\mathrm{CXCR}^{-1-}$ mice are susceptible to $\operatorname{EAE}[29,30]$; however, different underlying mechanisms were proposed. Liu et al. showed that CNS tissue damage is increased in $\mathrm{CXCR}^{-1-}$ mice in association with decreased production of interferon (IFN)- $\gamma$ and iNOS (inducible nitric oxide synthase) [29], whereas Muller et al. showed that the number of Foxp $3^{+}$regulatory $\mathrm{T}$ cells was reduced in the $\mathrm{CNS}$ of $\mathrm{CXCR}^{-1-}$ mice [30]. In contrast, several studies reported that blockade or genetic deficiency of either CXCR3 or its primary ligands had no impact [31] or detrimental effects on the manifestations of EAE [31-34]. Thus, the role of CXCR3 in EAE remains elusive. In this study, we demonstrated that $\mathrm{CXCR}^{-1-}$ mice are more susceptible to EAE. They also exhibit an increase in CNS-infiltrating Th17 cells during EAE, which reflects increased expansion of Th17 cells owing to increased numbers of glial cells in the CNS and an enhanced pro-Th17 cytokine/chemokine milieu produced by CXCR3-deficient CNS glial cells. Notably, our study is the first to demonstrate a critical role of CXCR3 in CNS glial cells rather than in CNSinfiltrating $\mathrm{T}$ cells in the pathogenesis of EAE.

\section{Methods}

Mice

The generation of $\mathrm{CXCR}^{-/-}$mice was described previously [35]. The mice used in these experiments were backcrossed to C57BL/6 for ten generations. For adoptivetransfer EAE experiments, littermates of C57BL/6 wildtype (WT) or $\mathrm{CXCR}^{-/-}$mice were used as donors and Thy $1.1^{+/+} \mathrm{C} 57 \mathrm{BL} / 6$ and Thy $1.1^{+/+} \mathrm{CXCR}^{-/-}$mice were used as recipients. All mice were bred under specific pathogen-free conditions at the animal center of the Institute of Biomedical Sciences (Academia Sinica, Taipei, Taiwan). All animal experiments were approved by the Institutional Animal Care and Utilization Committee at Academia Sinica and were performed in accordance with institutional guidelines.

\section{Cell line}

The glioblastoma cell line U87MG was obtained from Dr. Pang-Hsien Tu (Academia Sinica, Taipei, Taiwan) and cultured in Dulbecco's modified Eagle medium (DMEM; Life Technologies, Carlsbad, CA) supplemented with $10 \%$ fetal bovine serum (FBS; Life Technologies), $2 \mathrm{mM}$ L-glutamine, $1 \mathrm{mM}$ sodium pyruvate, $10 \mathrm{mM}$ HEPES ( $\mathrm{pH} 7.0$ ), and $0.1 \mathrm{mM}$ nonessential amino acids at $37{ }^{\circ} \mathrm{C}$ in a humidified $5 \% \mathrm{CO}_{2}$ atmosphere.

\section{Induction of EAE}

Mice (8-12 weeks old) were immunized subcutaneously in the hind limbs on day 0 with $100 \mu \mathrm{g}$ of myelin oligodendrocyte glycoprotein (MOG) $35-55$ peptide (MEVGW 
YRSPFSRVVHLYRNGK; MDBio, Taipei, Taiwan) in complete Freund's adjuvant (CFA) containing $400 \mu \mathrm{g}$ of heat-killed Mycobacterium tuberculosis H37RA (SigmaAldrich, St. Louis, MO). Two hundred nanograms of pertussis toxin (PTX) (List Biological Laboratories, Campbell, CA) was injected intraperitoneally on days 0 and 2. Mice were graded daily on a clinical scale of 0-6: 0 , no sign; 0.5 , partially flaccid tail; 1 , tail paralysis; 2 , impaired righting reflex or gait; 3 , partial hind limb paralysis; 4, total hind limb paralysis; 5 , hind limb paralysis with partial front limb weakness; and 6, moribundity or death.

\section{H\&E and LFB staining}

Mice were anesthetized and intracardially perfused with saline followed by $4 \%$ paraformaldehyde in phosphatebuffered saline (PBS). Spinal cords were embedded in paraffin and then cut into 5- $\mu \mathrm{m}$-thick transverse sections. Sections were deparaffinized, hydrated, and stained with hematoxylin and eosin (H\&E) and luxol fast blue (LFB). For LFB staining, sections were incubated with LFB solution at $60{ }^{\circ} \mathrm{C}$ overnight and then washed sequentially with $95 \%$ ethanol, water, $0.1 \%$ lithium carbonate solution, $70 \%$ ethanol, and water. The sections were then dehydrated with ethanol, rinsed with xylene, and mounted. In some experiments, sections stained with LFB were counterstained with cresyl violet.

\section{Confocal microscopy}

Sections were deparaffinized and hydrated with an ethanol series (100, 95, 90, 80, and $70 \%$, sequentially). The sections were then boiled in retrieval solution (Dako, Glostrup, Denmark) for $40 \mathrm{~min}$ and cooled to room temperature. After blocking with PBS containing $5 \%$ bovine serum albumen (BSA) and $0.2 \%$ Tween-20 at room temperature for $30 \mathrm{~min}$, sections were incubated at $4{ }^{\circ} \mathrm{C}$ overnight with a primary antibody to Iba1 (Wako, Osaka, Japan). The sections were then washed and incubated with species-specific secondary antibody conjugated with Alexa Fluor 568 (Life Technologies) together with Alexa Fluor 488-conjugated anti-glial fibrillary acidic protein (GFAP; clone GA5; eBioscience, San Diego, CA) at $4{ }^{\circ} \mathrm{C}$ overnight. The sections were washed with PBS, mounted with fluorescence mounting medium (Dako) containing $1 \mu \mathrm{g} / \mathrm{ml}$ of DAPI (4,6-diamidino-2phenylindole), and observed by confocal microscopy (LSM 700 system with a Plan Apochromat $\times 10$ objective; Carl Zeiss, Oberkochen, Germany). Images were acquired with ZEN software (Carl Zeiss), and data were analyzed using MetaMorph software (SPOT Imaging Solutions, Sterling Heights, MI).

To perform immunofluorescence staining of CXCR3 expression on glial cells in the spinal cord, spinal cords were embedded and frozen in OCT (Sakura, Alphen an den Rijn, Netherlands). Ten-micrometer transverse sections were warmed at room temperature for $10 \mathrm{~min}$, fixed in ice-cold acetone for $5 \mathrm{~min}$, and air-dried for 10 min. Sections were then washed with PBST $(0.05 \%$ Tween-20 in PBS) and blocked with PBST containing $5 \%$ BSA for $1 \mathrm{~h}$. After blocking, sections were stained with hamster anti-mouse CXCR3 (clone CXCR3-173; BioLegend, San Diego, CA) along with anti-GFAP-Alexa Fluor 647 (clone 2E1.E9; BioLegend) for detecting the expression of CXCR3 on astrocytes or with rabbit antimouse Iba1 (Wako) for detecting the expression of CXCR3 on microglia. After 4-h incubation, sections for detecting CXCR3 on microglia were washed with PBST and further incubated with biotin-conjugated goat antihamster IgG (clone Poly4055; BioLegend) along with goat anti-rabbit Alexa Fluor 568 (Thermo Fisher Scientific) for $2 \mathrm{~h}$ at room temperature followed by washing with PBST. All sections were then incubated with Alexa Fluor 488-conjugated streptavidin (BioLegend) for $2 \mathrm{~h}$ at room temperature. Finally, sections were incubated with $0.1 \%$ Suden black (Sigma-Aldrich) for $10 \mathrm{~min}$, washed, mounted, and inspected using confocal microscopy (LSM 700 system with a Plan Apochromat $\times 40$ objective). To perform immunofluorescence staining of IL-17 expression in the spinal cord during EAE, frozen sections were prepared, fixed, blocked as above, and followed by sequential staining with rat anti-mouse CD4 (BD Bioscience, Franklin Lake, NJ) and goat anti-mouse IL-17 (Santa Cruz Biotechnology, Dallas, TX), donkey anti-goat Alexa Fluor 488 (Thermo Fisher Scientific, Rockford, IL), biotin-conjugated donkey anti-rat IgG (Abcam, Cambridge, MA), and finally Alexa Fluor 555conjugated streptavidin (Thermo Fisher). The sections were inspected using confocal microscopy (LSM 700 system with a Plan Apochromat $\times 40$ objective).

\section{Th17 polarization and adoptive transfer}

For adoptive-transfer EAE experiments, donor mice were immunized as described above except without injection of PTX. Ten days after immunization, mice were sacrificed, and splenocytes were harvested and subjected to Th17-polarizing culture. Cells $\left(4 \times 10^{6} \mathrm{cell} / \mathrm{ml}\right)$ were cultured at $37{ }^{\circ} \mathrm{C}$ in a humidified $5 \% \mathrm{CO}_{2}$ atmosphere for $72 \mathrm{~h}$ in RPMI 1640 medium (Life Technologies) supplemented with $10 \%$ FBS (Thermo Scientific, Rockford, IL); $2 \mathrm{mM}$ L-glutamine; $50 \mu \mathrm{M}$ 2-mercaptoethanol (Merck, Whitehouse Station, NJ); $100 \mathrm{U} / \mathrm{ml}$ of penicillin and $100 \mu \mathrm{g} / \mathrm{ml}$ of streptomycin; $10 \mu \mathrm{g} / \mathrm{ml}$ of $\mathrm{MOG}_{35-55}$; Th17-polarizing cytokines, including IL-6 $(20 \mathrm{ng} / \mathrm{ml}$; R\&D Systems, Minneapolis, MN), IL-23 (20 ng/ml; R\&D Systems), and transforming growth factor (TGF) $\beta$ (5 ng/ml; PeproTech, Rocky Hill, NJ); and neutralizing antibodies against various cytokines (eBioscience), including IL-4 $(10 \mu \mathrm{g} / \mathrm{ml})$, IFN- $\gamma(10 \mu \mathrm{g} / \mathrm{ml})$, and IL-2 
$(10 \mu \mathrm{g} / \mathrm{ml})$. The cultured cells were harvested, and CD4 ${ }^{+}$ $\mathrm{T}$ cells were purified using magnetic-activated cellsorting (MACS) beads (Miltenyi Biotec, Auburn, CA). Th17 cells $\left(3 \times 10^{5}\right.$ cells per mouse for analysis of survival rate; $2 \times 10^{5}$ cells per mouse for cell cycle analyses) were intravenously injected into recipient mice that had been irradiated with a dose of 4 Gy. Recipient mice were immunized with $10 \mu \mathrm{g}$ of $\mathrm{MOG}_{35-55}$ peptide in CFA containing $50 \mu \mathrm{g}$ of $M$. tuberculosis and received $200 \mathrm{ng}$ of PTX intraperitoneally on days 0 and day 2. Mice were monitored daily, and clinical scores were graded.

\section{Isolation of CNS-infiltrating leukocytes}

Spinal cords were collected on days 0,10 , and 15 post-immunization for active EAE and on day 12 post-immunization for adoptive-transfer EAE. The spinal cord was excised, minced, and subjected to enzymatic digestion by incubating tissues in $1 \mathrm{ml}$ of digestion buffer containing serum-free RPMI medium supplemented with $0.5 \mathrm{mg} / \mathrm{ml}$ of collagenase IV (Sigma-Aldrich) and $1000 \mathrm{U} / \mathrm{ml}$ of DNase I (Calbiotech, Spring Valley, CA) for $30 \mathrm{~min}$ at $37{ }^{\circ} \mathrm{C}$. Cells were washed once with PBS containing $5 \%$ FBS, collected by centrifugation at $340 \times g$, and resuspended in $5 \mathrm{ml}$ of $30 \%$ Percoll solution (GE Healthcare Life Sciences, Piscataway, NJ). The $30 \%$ Percoll homogenate mix was layered over $70 \%$ Percoll followed by centrifugation at $2000 \times g$ for $20 \mathrm{~min}$ at room temperature. Leukocytes were collected from the $30 \% / 70 \%$ Percoll interface and, after washing three times with complete medium, were ready for immunostaining and cell cycle experiments.

\section{Flow cytometry analysis}

For intracellular cytokine staining, cells were stimulated with $20 \mathrm{ng} / \mathrm{ml}$ of phorbol 12-myristate 13-acetate (PMA; Sigma-Aldrich) and $1 \mu \mathrm{M}$ ionomycin (Sigma-Aldrich) in the presence of $10 \mu \mathrm{g} / \mathrm{ml}$ of brefeldin A (BioLegend) for $4 \mathrm{~h}$ at $37{ }^{\circ} \mathrm{C}$. Cells were then harvested, washed with fluorescence-activated cell-sorting (FACS) buffer (HBSS containing $1 \%$ FBS and HEPES, pH 7.0), and incubated with anti-CD16/CD32 (2.4G2, BD Bioscience) at $4{ }^{\circ} \mathrm{C}$ for $15 \mathrm{~min}$ followed by surface staining with anti-CD4-APC$\mathrm{Cy} 7$ or anti-CD4-APC (RM4-5; BioLegend) at $4{ }^{\circ} \mathrm{C}$ for $15 \mathrm{~min}$. After two washes with PBS, cells were stained with fixable viability dye conjugated with eFluor 780 (eBioscience) at $4{ }^{\circ} \mathrm{C}$ for $15 \mathrm{~min}$, washed with PBS buffer, and fixed with $2 \%$ paraformaldehyde at $4{ }^{\circ} \mathrm{C}$. After a 1 $\mathrm{h}$ fixation, cells were washed with intracellular staining (IC) buffer containing $1 \%$ BSA and $0.1 \%$ saponin (SigmaAldrich) in PBS at $4{ }^{\circ} \mathrm{C}$. Cells were then incubated with $2 \%$ normal rat serum (eBioscience) in IC buffer for 30 min followed by intracellular staining with anti-IL-17PerCp-Cy5.5 (TC11-18H10.1; BioLegend) and anti-IFN- $\gamma$ PE (XMG1.2; BioLegend) at room temperature for
30 min. After two washes with FACS buffer, cells were subjected to FACS analysis. For surface staining of CXCR3 expression on U87MG cells, cells were stained with antiCXCR3-APC (CXCR3-173; BioLegend) followed by FACS analysis. FACS analyses were performed using the LSRII system (BD Biosciences), and data were analyzed using FlowJo software (Tree Star, Ashland, OR).

\section{Cell cycle analysis of CNS-infiltrating leukocytes}

For cell cycle analysis of CNS-infiltrating cells, mice were intraperitoneally injected with $1 \mathrm{mg}$ of $\mathrm{BrdU}$ (BD Biosciences) on day 11 post-immunization with MOG. Twenty-four hours after BrdU injection, CNS-infiltrating leukocytes were isolated, cultured for $4 \mathrm{~h}$, and subjected to cell cycle analysis using a BrdU Flow Kit according to the manufacturer's instructions (BD Biosciences). Briefly, cells were harvested, immunostained with anti-CD4APC-Cy7, washed and fixed with Cytofix/Cytoperm buffer at $4{ }^{\circ} \mathrm{C}$ for $30 \mathrm{~min}$, washed with Perm/Wash buffer, resuspended in Cytoperm Plus buffer at $4{ }^{\circ} \mathrm{C}$ for $10 \mathrm{~min}$, and washed again. Cells were fixed once more with Cytofix/Cytoperm buffer at room temperature for $5 \mathrm{~min}$ followed by several washes. Cells were then treated with DNase $(300 \mu \mathrm{g} / \mathrm{ml})$ for $1 \mathrm{~h}$ at $37{ }^{\circ} \mathrm{C}$, washed, and stained with anti-IL-17-PerCp-Cy5.5, anti-IFN- $\gamma$-PE, and antiBrdU-FITC for $20 \mathrm{~min}$ at $37{ }^{\circ} \mathrm{C}$. Finally, cells were washed, resuspended in $1 \mathrm{ml}$ of FACS buffer containing 7-AAD (7-aminoactinomycin D), and subjected to FACS analysis.

\section{Generation of primary microglia and astrocytes from neonatal mice}

The cerebral cortex was dissected from a neonatal mouse (1-day old) brain, placed in HBSS containing $100 \mathrm{U} / \mathrm{ml}$ of penicillin and $100 \mu \mathrm{g} / \mathrm{ml}$ of streptomycin, and mechanically disrupted by gently pipetting. Cells were cultured in DMEM supplemented with $10 \%$ FBS (Life Technologies), $2 \mathrm{mM}$ L-glutamine, $100 \mathrm{U} / \mathrm{ml}$ of penicillin, $100 \mu \mathrm{g} / \mathrm{ml}$ of streptomycin, OPI media supplement $(1 \mathrm{mM}$ oxaloacetate, $0.45 \mathrm{mM}$ pyruvate, $0.2 \mathrm{U} / \mathrm{ml}$ of insulin; Sigma-Aldrich), and $0.5 \mathrm{ng} / \mathrm{ml}$ of granulocyte/ macrophage-colony stimulating factor (GM-CSF; PeproTech) in a $75 \mathrm{~T}$ flask coated with poly-L-lysine (SigmaAldrich) at $37{ }^{\circ} \mathrm{C}$ in a humidified $5 \% \mathrm{CO}_{2}$ atmosphere. The medium was completely replaced with fresh medium on day 1 , and half of the medium was replaced with fresh medium on days 4,7 , and 10 . On day 12 , microglia were obtained by vigorously slapping the flask to dislodge microglia attached to the astrocyte monolayer. Adherent astrocytes were subjected to trypsinEDTA digestion, washed, and collected. The purity of microglia and astrocytes was determined by surface staining with anti-CD11b (clone M1/70; eBioscience) for microglia and by intracellular staining with anti-GFAP 
(clone GA5; eBioscience) for astrocytes. Both cell preparations were $>90 \%$ pure. Isolated microglia and astrocytes $\left(2 \times 10^{5}\right.$ cells $\left./ \mathrm{ml}\right)$ were plated in DMEM supplemented with $10 \% \mathrm{FBS}, 2 \mathrm{mM}$ L-glutamine, $100 \mathrm{U} / \mathrm{ml}$ of penicillin, $100 \mu \mathrm{g} / \mathrm{ml}$ of streptomycin and OPI, and cultured overnight, followed by incubation with or without lipopolysaccharide (LPS) (100 ng/ml; Sigma-Aldrich) for $24 \mathrm{~h}$. Culture supernatants were collected for analysis of cytokines by enzyme-linked immunosorbent assay (ELISA).

\section{ELISA}

The levels of IL-23p19 (eBioscience) and CCL20 (R\&D Systems) in culture supernatants were measured by ELISA according to the manufacturers' instructions.

\section{RT-PCR}

Total RNA was extracted from the spinal cord using the TRIzol reagent (Life Technologies) according to the manufacturer's instructions. Total RNA was reversed transcribed into complementary DNA (cDNA) using SuperScript III reverse transcriptase (Life Technologies) and random hexamer primers according to the manufacturer's instructions. The cDNA was subjected to quantitative real-time reverse transcription polymerase chain reaction (RT-qPCR) using TaqMan Gene Expression Assays (Applied Biosystems, Foster City, CA) for analysis of the target genes, IL-23p19, CCL20, IL-17, GM-CSF, CXCL9, and CXCL10; GAPDH (glyceraldehyde-3-phosphate dehydrogenase) was used as an internal control. The thermal cycling protocol entailed initial heating at $95{ }^{\circ} \mathrm{C}$ for 10 min followed by 40 cycles of $95{ }^{\circ} \mathrm{C}$ for $1 \mathrm{~min}$ and $60{ }^{\circ} \mathrm{C}$ for $1 \mathrm{~min}$. The resultant PCR products were measured using an ABI prism 7500 Sequence Detection System (Applied Biosystems). The levels of target messenger RNAs (mRNAs), normalized to the level of $G A P D H$, were analyzed using the $\triangle \triangle \mathrm{Ct}$ method.

\section{Western blotting}

U87MG cells $\left(10^{6}\right)$ were serum-starved for $6 \mathrm{~h}$ in fasting medium (DMEM supplemented with $0.5 \%$ BSA, $2 \mathrm{mM}$ L-glutamine, $1 \mathrm{mM}$ sodium pyruvate, $10 \mathrm{mM}$ HEPES $\mathrm{pH}$ 7.0, and $0.1 \mathrm{mM}$ nonessential amino acids) followed by treatment with $100 \mathrm{ng} / \mathrm{ml}$ of CXCL10 (PeproTech) prior to stimulation with or without $100 \mathrm{ng} / \mathrm{ml}$ of IL-17 (R\&D Systems). Cells were lysed in a lysis buffer containing $25 \mathrm{mM}$ Tris (pH 7.4), $150 \mathrm{mM} \mathrm{NaCl}, 1 \mathrm{mM}$ EDTA, 1 mM EGTA, $1 \%$ Triton X-100, protease inhibitor cocktail (EMD Millipore, Billerica, MA), and phosphatase inhibitor cocktail (Sigma-Aldrich). Proteins in cell lysates were resolved by sodium dodecyl sulfatepolyacrylamide gel electrophoresis (SDS-PAGE) on $10 \%$ gels followed by Western blot analysis using antibodies against extracellular signal-regulated kinase (ERK), phospho-ERK, ІкB, phospho-IкB, NF-кB p65, poly-
(ADP-ribose) polymerase (PARP; all from Cell Signaling Technology, Beverly, MA), and $\alpha$-tubulin (Abcam).

\section{Subcellular fractionation}

Cells were harvested, washed with PBS, pelleted, and resuspended in hypotonic buffer (10 mM HEPES pH 7.9, $1.5 \mathrm{mM} \mathrm{MgCl}_{2}, 10 \mathrm{mM} \mathrm{KCl}, 0.5 \mathrm{mM}$ DTT, protease inhibitor cocktail) and incubated on ice for $15 \mathrm{~min}$. After incubation, $10 \% \mathrm{NP}-40$ was added to the cell suspensions $(1 / 16, v / v)$ and mixed by vortexing for $10 \mathrm{~s}$. The lysates were then centrifuged at $12,000 \times g$ at $4{ }^{\circ} \mathrm{C}$ for 5 min to pellet nuclei, and supernatants were collected as the cytoplasmic fraction. The nuclear pellets were washed twice with hypotonic buffer and then resuspended in hypertonic buffer (20 mM HEPES pH 7.9, $1.5 \mathrm{mM} \mathrm{MgCl} 2,420 \mathrm{mM} \mathrm{NaCl}, 25 \%$ glycerol, protease inhibitor cocktail). Nuclear lysates were incubated at $4{ }^{\circ} \mathrm{C}$ for $15 \mathrm{~min}$ followed by centrifugation at $12,000 \times g$ for 5 min at $4{ }^{\circ} \mathrm{C}$. Supernatants were collected as the nuclear fraction. Both cytoplasmic and nuclear fractions were subjected to SDS-PAGE followed by Western blot analysis.

\section{Statistical analysis}

Data are presented as means \pm SEM. Because the sample size is small ( $<30$ samples) and the data is not normally distributed evaluated by Shapiro-Wilk test, we used Mann-Whitney $U$ test to evaluate the significance of differences between two experimental results. The Log-rank test was used for the analysis of survival rates. A $P<0.05$ was considered statistically significant.

\section{Results}

\section{$\mathrm{CXCR3}^{-1-}$ mice develop more severe EAE}

To examine the impact of CXCR3 on the development of EAE, we induced $\mathrm{EAE}$ in WT and $\mathrm{CXCR}^{-/-}$mice and determined the kinetics of disease onset and severity. Both WT and $\mathrm{CXCR}^{-/-}$mice developed a monophasic disease characterized by ascending paralysis from day 12 to day 15 after immunization followed by a gradual recovery (Fig. 1a). CXCR3 ${ }^{-/-}$mice had slightly earlier disease onset (day 12) compared with WT mice (day 13.8), and the overall disease development was significantly more severe in $\mathrm{CXCR}^{-1-}$ mice than in WT mice $(P<0.05$, Fig. 1a). We further performed LFB staining to examine demyelinating lesions and leukocyte infiltration in the spinal cord of WT and $\mathrm{CXCR}^{-/-}$mice. Equivalent sections of lumbar spinal cords from WT and CXCR3 $3^{-/-}$ were compared, and $\mathrm{CXCR}^{-/-}$mice exhibited substantial demyelination accompanied by an increase in inflammation in the spinal cord compared with WT mice (Fig. 1b). The comparison of demyelination and inflammation in serial sections from lumbar spinal cords of WT and $\mathrm{CXCR}^{-1-}$ mice is also shown in Additional file 1: Figure S1, and sections of the spinal cords from $\mathrm{CXCR}^{-1-}$ 



Fig. $1 \mathrm{CXCR}^{-/-}$mice develop more severe EAE. EAE was induced in WT $(n=11)$ and $\mathrm{CXCR}^{-/-}(n=11)$ mice by immunizing with MOG/CFA. a Clinical scores of WT and CXCR3 ${ }^{-1-}$ mice at various times after immunization are shown. Data are representative of six independent experiments $\left({ }^{*} P<0.05\right)$. b Sections of the lumbar spinal cord (original magnification $\times 100$ ) collected from WT and $C X C R 3^{-/-}$mice at the peak of disease (day 15) were fixed and subjected to LFB staining followed by counterstaining with cresyl violet for detection of demyelination (blue) and inflammation (purple). Arrows indicate infiltrating leukocytes. $n$ stands for the number of mice

mice consistently showed more severe demyelination and inflammation as compared with WT mice.

\section{$\mathrm{CXCR}^{-/-}$mice exhibit significantly increased CNS- infiltrating Th17 cells during EAE}

Given that EAE is a T cell-mediated inflammatory disease, we examined the subsets of infiltrating $\mathrm{CD} 4^{+}$effector $\mathrm{T}$ cells in the spinal cord at the peak of disease (day 15). Mononuclear cells were isolated from the spinal cords on day 15 post-immunization and immunostained for surface CD4 and intracellular IL-17 and IFN- $\gamma$ by FACS. The gating strategy of FACS analysis is shown in Fig. 2a. Total CNS-infiltrating leukocytes were significantly increased in $\mathrm{CXCR}^{-1-}$ mice compared with WT mice $(P<0.01$, Fig. $2 \mathrm{~b})$, as were the total numbers of all $\mathrm{CD}_{4}^{+} \mathrm{T}$ cells infiltrating the spinal cord $(P<0.05$, Fig. $2 \mathrm{c})$. The increase in infiltrating $\mathrm{CD} 4^{+}$cells was further analyzed based on subpopulations. Infiltrating $\mathrm{CD} 4^{+} \mathrm{IFN}-\gamma^{+}$(Th1) cells were comparable between $\mathrm{CXCR}^{-/-}$mice and WT mice (Fig. 2d), whereas infiltrating $\mathrm{CD}_{4}^{+} \mathrm{IL}_{-17^{+}}$(Th17) cells were significantly increased in $\mathrm{CXCR}^{-/-}$mice compared with WT mice $(P<0.001$, Fig. 2e). The immunofluorescence staining of Th17 cells in frozen tissue sections of the spinal cord is also performed and shown in Additional file 2: Figure S2.

\section{$\mathrm{CXCR3}^{-/-}$mice adoptively transferred with Th 17 cells polarized from $\mathrm{CD}^{+} \mathrm{T}$ cells of MOG-immunized $\mathrm{CXCR3}^{-1-}$ mice are significantly more susceptible to EAE}

Having established that infiltrating Th17 cells in the $\mathrm{CNS}$ are increased in $\mathrm{CXCR}^{-1-}$ mice compared with
WT mice during EAE (Fig. 2), we next addressed whether Th17 cells polarized from $\mathrm{CXCR}^{-/-} \mathrm{CD}^{+} \mathrm{T}$ cells were more detrimental for EAE development by performing adoptive-transfer EAE experiments. Donor WT or $\mathrm{CXCR}^{-/-}$mice were immunized with MOG, and splenocytes were collected at the subclinical phase (10 day post-immunization). Splenocytes were cultured with MOG under Th17-polarizing conditions followed by purification of $\mathrm{CD}^{+}{ }^{+} \mathrm{T}$ cells. Polarized Th17 cells from WT or $\mathrm{CXCR}^{-/-}$mice were adoptively transferred into irradiated WT or $\mathrm{CXCR}^{-/-}$recipient mice followed by immunization with a suboptimal dose of MOG. WT recipient mice receiving Th17 cells polarized from $\mathrm{CXCR}^{-/-} \mathrm{CD}^{+}{ }^{+} \mathrm{T}$ cells $\left(\mathrm{CXCR} 3^{-/-} \rightarrow \mathrm{WT}\right)$ showed a survival rate comparable to that of WT mice receiving Th17 cells polarized from WT $\mathrm{CD}^{+} \mathrm{T}$ cells (WT $\rightarrow$ WT) (Fig. 3a, left panel). Similarly, $\mathrm{CXCR}^{-1-}$ recipient mice receiving Th17 cells polarized from $\mathrm{CXCR}^{-/-}$ $\mathrm{CD}^{+}{ }^{+} \mathrm{T}$ cells $\left(\mathrm{CXCR}^{-/-} \rightarrow \mathrm{CXCR}^{-/-}\right.$) showed a survival rate comparable to that of $\mathrm{CXCR}^{-1-}$ recipient mice receiving Th17 cells polarized from WT $\mathrm{CD}^{+}{ }^{+} \mathrm{T}$ cells $\left(\mathrm{WT} \rightarrow \mathrm{CXCR}^{-/-}\right.$) (Fig. 3a, right panel). These results suggest that Th17 cells polarized from WT or CXCR3 ${ }^{-/-}$ $\mathrm{CD}^{+} \mathrm{T}$ cells may not be responsible for the severity of disease observed in $\mathrm{CXCR}^{-/-}$mice. However, we noted that survival rates were always low in cases where recipients were $\mathrm{CXCR}^{-/-}$mice (Fig. 3a, left panel vs. right panel). Applying another approach for comparing the survival rate between $\mathrm{WT}$ and $\mathrm{CXCR}^{-/-}$recipient mice, we found that irradiated $\mathrm{CXCR}^{-1-}$ recipient mice 


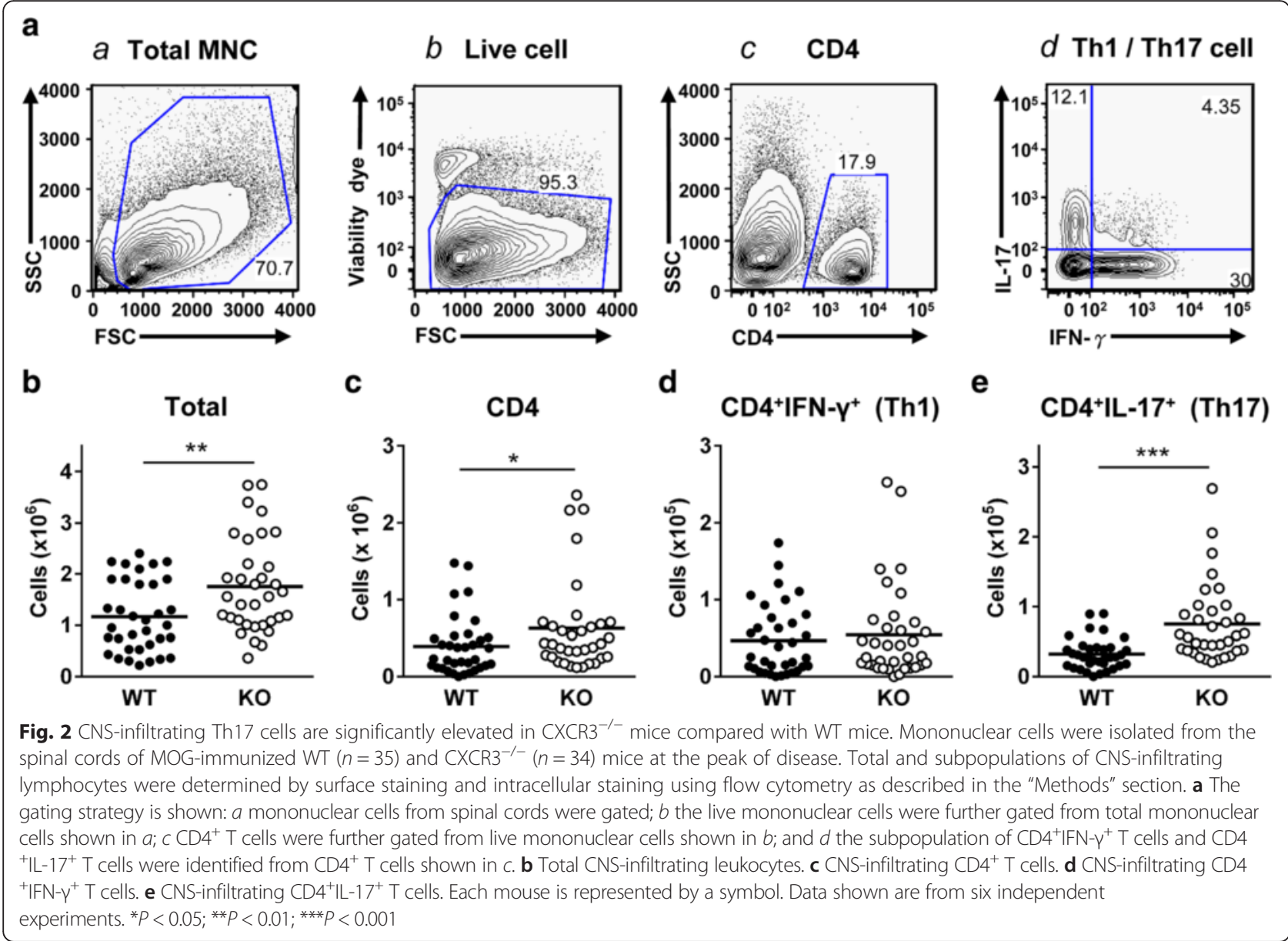

adoptively transferred with Th17 cells polarized from WT or $\mathrm{CXCR}^{-/-} \mathrm{CD}^{+} \mathrm{T}$ cells always showed significantly increased morbidity compared with irradiated WT recipient mice receiving polarized Th17 cells from the same origin $(P<0.05$; Fig. $3 \mathrm{~b})$. Because both WT and $\mathrm{CXCR}^{-/-}$mice received identical Th17 cells, the only difference that could account for the more severe EAE is the specific CNS microenvironment in the recipient mice. Taken together, these results demonstrate that Th17 cells polarized from either WT or CXCR3 ${ }^{-/-} \mathrm{CD} 4^{+} \mathrm{T}$ cells do not significantly contribute to the disease severity of $\mathrm{CXCR}^{-1-}$ mice; instead, the $\mathrm{CNS}$ milieu in $\mathrm{CXCR}^{-1-}$ mice is mainly responsible. On the basis of these results, we conclude that CXCR3 expressed on CNS-resident cells negatively regulates EAE pathogenesis.

\section{$\mathrm{CXCR3}^{-/-}$recipient mice show increased CNS-infiltrating} Th17 cells compared with WT recipient mice in adoptivetransfer EAE

Given that $\mathrm{CXCR}^{-1-}$ mice show more severe EAE and significantly increased infiltrating Th17 cells (Fig. 2), and that disease severity in $\mathrm{CXCR}^{-1-}$ mice is associated with the CNS milieu (Fig. 3), we next investigated whether the CNS milieu in $\mathrm{CXCR}^{-/-}$was favorable for CNSinfiltrating Th17 cells. To this end, we performed adoptive-transfer EAE experiments in which Th17 cells polarized from WT or $\mathrm{CXCR}^{-/-}$mice were adoptively transferred into irradiated WT or $\mathrm{CXCR}^{-/-}$recipient mice followed by immunization with a suboptimal dose of MOG. Following transfer of Th17 cells of the same origin polarized either from WT or $\mathrm{CXCR}^{-/-} \mathrm{CD}^{+} \mathrm{T}$ cells, $\mathrm{CXCR}^{-/-}$recipient mice showed a significant increase in total CNS-infiltrating leukocytes $(P<0.01$ for $\mathrm{WT} \rightarrow \mathrm{WT}$ vs. WT $\rightarrow \mathrm{CXCR}^{-/-}$and $\mathrm{CXCR}^{-/-} \rightarrow \mathrm{WT}$ vs. $\mathrm{CXCR}^{-1-} \rightarrow \mathrm{CXCR}^{-1-}$; Fig. $\left.4 \mathrm{a}\right)$ and $\mathrm{CD} 4^{+}$T cells $(P$ $<0.01$ for WT $\rightarrow$ WT vs. WT $\rightarrow \mathrm{CXCR}^{-1-}$ and $P<0.05$ for $\mathrm{CXCR3}^{-/-} \rightarrow$ WT vs. $\mathrm{CXCR3}^{-1-} \rightarrow \mathrm{CXCR}^{-1-}$; Fig. $4 \mathrm{~b}$ ) compared with WT recipient mice. Furthermore, the total number of CNS-infiltrating Th1 cells was comparable (Fig. 4c), whereas Th17 cells were significantly elevated in $\mathrm{CXCR}^{-1-}$ recipient mice compared with WT recipient mice $(P<0.001$ for WT $\rightarrow$ WT vs. WT $\rightarrow$ $\mathrm{CXCR}^{-/-}$and $P<0.0001$ for $\mathrm{CXCR}^{-/-} \rightarrow \mathrm{WT}$ vs. $\mathrm{CXCR3}^{-1-} \rightarrow \mathrm{CXCR}^{-1-}$; Fig. 4d). These results show that 



Fig. 3 A CXCR3-deficient CNS milieu is responsible for the higher susceptibility of $\mathrm{CXCR3}^{-/}$mice to EAE. Splenocytes isolated from MOG-immunized WT or $\mathrm{CXCR}^{-1-}$ mice on day 10 post-immunization were cultured under Th17-polarizing conditions in the presence of MOG IL-6, IL-23, and TGF- $\beta$ for $72 \mathrm{~h}$. Cultured CD4 ${ }^{+} \mathrm{T}$ cells were purified by MACS-positive selection, and $3 \times 10^{5} \mathrm{CD} 4^{+} \mathrm{IL}-17^{+}$cells were transferred into irradiated (4 Gy) WT or CXCR3 ${ }^{-1-}$ mice followed by immunization with a suboptimal dose of MOG/CFA $(10 \mu \mathrm{g} / 50 \mu \mathrm{g})$ and injection of PTX ( $200 \mathrm{ng} / \mathrm{ml}$; day 0 and day 2). Four adoptive-transfer EAE experiments were performed: (1) WT (Th17) $\rightarrow$ WT, (2) WT (Th17) $\rightarrow \mathrm{CXCR3}^{-1-}$, (3) $\mathrm{CXCR3}^{-/-}$(Th17) $\rightarrow \mathrm{WT}$, and (4) $\mathrm{CXCR3}^{-/-}$(Th17) $\rightarrow \mathrm{CXCR3}^{-1-}$. Survival rates of recipient WT and $\mathrm{CXCR3}^{-1-}$ mice at various times postimmunization are shown. a Comparison of transfer of polarized Th17 cells with different origins into WT recipient mice $\left(\mathrm{WT} \rightarrow W T\right.$ vs. CXCR3 ${ }^{-1-}$ $\rightarrow \mathrm{WT}$, left panel) or $\mathrm{CXCR3}^{-/-}$recipient mice $\left(\mathrm{WT} \rightarrow \mathrm{CXCR}^{-/-} \mathrm{vs}\right.$. $\mathrm{CXCR3}^{--} \rightarrow \mathrm{CXCR3}^{-/-}$, right panel). $\mathbf{b}$ Comparison of transfer of polarized Th17 cells with the same origins into WT or CXCR3 ${ }^{-1}$ recipient mice $\left(\mathrm{WT} \rightarrow \mathrm{WT}\right.$ vs. $\mathrm{WT} \rightarrow \mathrm{CXCR3}^{-1-}$, left panel; CXCR3 $\rightarrow$ WT vs. $\mathrm{CXCR}^{-1-} \rightarrow \mathrm{CXCR}^{-1-}$, right panel). Data shown are from two independent experiments (12 mice for each adoptive-transfer EAE group). ${ }^{*} P<0.05 ;{ }^{* *} P<0.01 ;{ }^{* * *} P<0.001$

a CXCR3-deficient CNS milieu indeed promotes better expansion of Th17 cells, regardless of their origin, than a WT CNS milieu.

Although WT or $\mathrm{CXCR}^{-1-}$ mice receiving Th17 cells polarized from $\mathrm{CXCR}^{-1-}{ }^{-} \mathrm{CD} 4^{+} \mathrm{T}$ cells showed a tendency toward an increased number of CNS-infiltrating Th17 cells compared with mice that received Th17 cells polarized from WT $\mathrm{CD} 4^{+} \mathrm{T}$ cells $\left(\mathrm{CXCR}^{-/-} \rightarrow \mathrm{WT}\right.$ vs. $\mathrm{WT} \rightarrow \mathrm{WT}$ and $\mathrm{CXCR}^{-1-} \rightarrow \mathrm{CXCR}^{-1-}$ vs. WT $\rightarrow$ $\mathrm{CXCR}^{-1-}$ ), this difference did not reach statistical difference (Fig. 4d). Notably, the rank order of increased
CNS-infiltrating Th17 cells in adoptive-transfer EAE was $\mathrm{CXCR}^{-/-} \rightarrow \mathrm{CXCR}^{-/-}>\mathrm{WT} \rightarrow \mathrm{CXCR}^{-/-}>\mathrm{CXCR}^{-/-}$ $\rightarrow \mathrm{WT}>\mathrm{WT} \rightarrow \mathrm{WT}$, further supporting the conclusion that a CXCR3-deficient CNS milieu has a greater impact on Th17 expansion during EAE than Th17 cells derived from CXCR3-deficient $\mathrm{CD}^{+} \mathrm{T}$ cells. The gating strategy for FACS analysis of total lymphocytes, $\mathrm{CD} 4^{+} \mathrm{T}$ cells, $\mathrm{CD} 4^{+} \mathrm{IFN}-\gamma^{+}$, and $\mathrm{CD} 4^{+} \mathrm{IL}-17^{+}$is shown in Additional file 3: Figure S3

\section{Th17 cells infiltrating the spinal cord of $\mathrm{CXCR}^{-/-}$mice show increased proliferation compared to those infiltrating the spinal cord of WT mice}

Since adoptive-transfer EAE experiments showed that the number of Th17 cells is significantly increased in the CXCR3-deficient CNS milieu compared with the WT CNS milieu (Fig. 4), we hypothesized that Th17 cells would proliferate better in a CXCR3-deficient CNS milieu. To test this hypothesis, we performed a cell cycle analysis of infiltrating $\mathrm{CD} 4^{+} \mathrm{T}$ cells in the spinal cord in the aforementioned adoptive-transfer EAE experiments (Fig. 4) by injecting recipient mice with BrdU and harvesting CNS-infiltrating cells $24 \mathrm{~h}$ later. The CNSinfiltrating cells were subjected to cell cycle analysis by immunostaining with fluorochrome-conjugated antiBrdU and 7-ADD. As shown in Fig. 5a, a significantly higher percentage of WT CD4 $4^{+} \mathrm{T}$ cells were in $\mathrm{S}$ phase when adoptively transferred into $\mathrm{CXCR}^{-/-}$recipient mice than into WT recipient mice $(P<0.01$ for WT $\rightarrow$ WT vs. WT $\rightarrow \mathrm{CXCR}^{-/-}$; Fig. 5b). Similarly, CXCR3 ${ }^{-1-}$ $\mathrm{CD}^{+} \mathrm{T}$ cells showed a significantly higher percentage of cells in $\mathrm{S}$ phase when adoptively transferred into CXCR3 ${ }^{-/-}$ recipient mice than into WT recipient mice $(P<0.05$ for $\mathrm{CXCR}^{-/-} \rightarrow \mathrm{WT}$ vs. $\mathrm{CXCR}^{-1-} \rightarrow \mathrm{CXCR}^{-/-}$; Fig. $\left.5 \mathrm{~b}\right)$. No significant difference was observed in the percentages of cells in G0/G1, G2/M, or apoptosis phases among these four groups of recipient mice (Fig. 5b). We further analyzed the number of CD4 $4^{+} \mathrm{IL}-17^{+} \mathrm{T}$ cells in $\mathrm{S}$ phase. As expected, the number of $\mathrm{CD} 4^{+} \mathrm{IL}-17^{+} \mathrm{T}$ cells in $\mathrm{S}$ phase was significantly increased in $\mathrm{CXCR}^{-/-}$recipient mice compared with WT recipient mice $(P<0.001$ for WT $\rightarrow$ WT vs. WT $\rightarrow \mathrm{CXCR}^{-/-}$and $\mathrm{CXCR}^{-/-} \rightarrow \mathrm{WT}$ vs. $\mathrm{CXCR}^{-/-} \rightarrow$ $\mathrm{CXCR}^{-/-}$; Fig. 5c). The rank order of the increase in CNSinfiltrating Th17 cells in adoptive-transfer EAE experiments $\mathrm{CXXR}^{-/-} \rightarrow \mathrm{CXCR}^{-/-}>\mathrm{WT} \rightarrow \mathrm{CXCR}^{-/-}>\mathrm{CXCR}^{-/-}$

$\rightarrow$ WT $>$ WT $\rightarrow$ WT; Fig. 4d) is consistent with the rank order of $\mathrm{CD}^{+} \mathrm{IL}^{-17^{+}} \mathrm{T}$ cell proliferation $\left(\mathrm{CXCR}^{-/-} \rightarrow\right.$ $\mathrm{CXCR}^{-/-}>\mathrm{WT} \rightarrow \mathrm{CXCR}^{-/-}>\mathrm{CXCR}^{-/-} \rightarrow \mathrm{WT}>\mathrm{WT}$

$\rightarrow$ WT; Fig. 5c). These results suggest that the CXCR3deficient CNS milieu has a greater impact on the increase in CNS-infiltrating Th17 cells observed in $\mathrm{CXCR}^{-/-}$mice than does the increased proliferative capability of Th17 cells polarized from CXCR3-deficient $\mathrm{CD} 4^{+} \mathrm{T}$ cells. The gating 

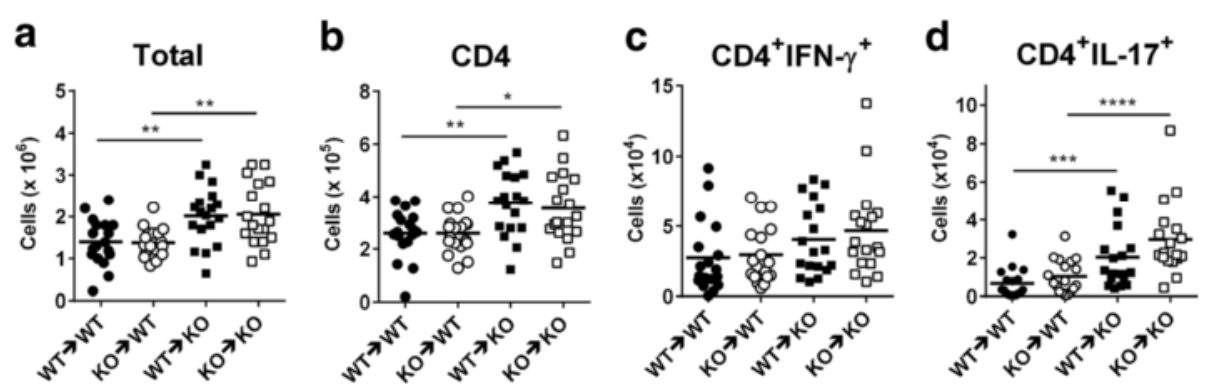

Fig. $4 \mathrm{CXCR3}^{-1-}$ recipient mice show increased CNS-infiltrating Th17 cells. Adoptive-transfer EAE was performed as described in Fig. 3, except that $2 \times 10^{5}$ donor $\mathrm{CD}^{+} \mathrm{IL}-17^{+}$cells were used for adoptive-transfer experiments $\mathrm{WT} \rightarrow \mathrm{WT}$ and $\mathrm{WT} \rightarrow \mathrm{CXCR3^{-/- }}, 18$ recipient mice for each group; $\mathrm{CXCR3}^{-/-} \rightarrow \mathrm{WT}$ and $\mathrm{CXCR3}^{---} \rightarrow \mathrm{CXCR}^{-/-}, 19$ recipient mice for each group). Spinal cords were collected from recipient mice on day 12 postimmunization, and CNS-infiltrating cells were isolated. Different subsets of T cells were identified by surface and intracellular staining using flow cytometry. a Total CNS-infiltrating leukocytes. b CNS-infiltrating CD4 ${ }^{+} T$ cells. $\mathbf{c} C N S$-infiltrating CD4 ${ }^{+} I F N-\gamma^{+} T$ cells. $\mathbf{d} C N S$-infiltrating CD4 ${ }^{+} I L-17^{+}$ T cells. Each mouse is represented by a symbol. Data shown are from three independent experiments. ${ }^{*} P<0.05$; ${ }^{* *} P<0.01 ;{ }^{* * *} P<0.001$; ${ }^{* * * *} P<0.0001$. The gating strategy for the FACS analysis of this figure is shown in Additional file 3: Figure $\mathrm{S3}$

strategy for FACS analysis of cell cycle phase of $\mathrm{CD}^{+} \mathrm{T}$ cells is shown in Additional file 4: Figure S4.

The results from Figs. 4 and 5 show that the increase in CNS-infiltrating Th17 cells in $\mathrm{CXCR}^{-/-}$mice during EAE is likely attributable to the extrinsic effect of a proTh17 milieu generated by the CXCR3-deficient CNS. Notably, although CXCR3 mainly regulates effector lymphocyte trafficking to inflamed tissues, our current study provides the first demonstration that a CXCR3 deficiency in the CNS has a greater impact on the pathogenesis of EAE.

Cytokines required for Th17 expansion and recruitment are significantly increased in the spinal cord in $\mathrm{CXCR3}^{-/-}$ mice compared with WT mice

Having found that a CXCR3-deficient CNS milieu promotes Th17 cell expansion (Figs. 4 and 5), we next examined whether a CXCR3 deficiency generates a CNS microenvironment preferential for Th17 proliferation, survival, maintenance, and recruitment. An analysis of cytokine gene expression in the spinal cord from MOGimmunized WT and $\mathrm{CXCR}^{-/-}$mice on days 0,10 (preclinical phase), and 14 (peak phase) revealed that mRNAs for cytokines required for the expansion of Th17 cells were significantly increased in the spinal cord of $\mathrm{CXCR}^{-/-}$mice compared with WT mice at both preclinical (day 10) and peak (day 14) phases (Fig. 6). The expression levels of cytokine genes $I L-6, I L-23 p 19, G M-$ CSF, and $I L-17$ responsible for the expansion of Th17 cells (Fig. 6a) and chemokine gene CCL2O (Fig. 6b) responsible for the recruitment of Th17 cells into inflammatory sites were significantly elevated in the spinal cord of $\mathrm{CXCR}^{-/-}$mice. The levels of mRNAs for the CXCR3 ligands CXCL9 and CXCL10 were also significantly increased (Fig. 6b).

\section{CXCR3-deficient glial cells stimulated with LPS} significantly increase IL-23 and CCL20 secretion Given that production of pro-Th17 cytokines is increased in the CXCR3-deficient spinal cord (Fig. 6) and that glial cells, astrocytes and microglia, in CNS parenchymal tissues express CXCR3 [26, 28, 36], we further examined whether glial cells lacking CXCR3 preferentially produced cytokines required for Th17 cell generation and recruitment during inflammation. Primary glial cells were isolated from the cortex of neonatal mouse brains and differentiated into microglia and astrocytes. Microglia and astrocytes were stimulated with lipopolysaccharide (LPS) followed by an analysis of the secretion of IL-23 and CCL20, which are required for the expansion and recruitment of Th17 cells, respectively. As shown in Fig. 7, both astrocytes (Fig. 7a) and microglia (Fig. 7b) differentiated from the CXCR3 ${ }^{-1-}$ brain cortex showed increased levels of IL-23 and CCL20 compared with those differentiated from WT mice. Primary glial cells isolated from $\mathrm{CXCR}^{-1-}$ mice produced greater amounts of cytokines compared with those isolated from WT mice (Fig. 7), suggesting an intrinsic increase in pro-Th17 cytokines in CXCR3deficient glial cells.

\section{$\mathrm{CXCR}^{-/-}$mice exhibit a significant increase in the} number of glial cells in the spinal cord compared with WT mice during EAE

The levels of cytokines that favor Th17 cell expansion and recruitment were significantly increased in the spinal cord of $\mathrm{CXCR}^{-1-}$ mice compared with WT mice (Fig. 6). This increase could result from enhanced cytokine production by CXCR3-deficient glial cells and/or an increase in the number of glial cells in the spinal cord of $\mathrm{CXCR}^{-1-}$ mice during EAE. The pro-Th17 cytokine production in CXCR3-deficient glial cells was significantly 


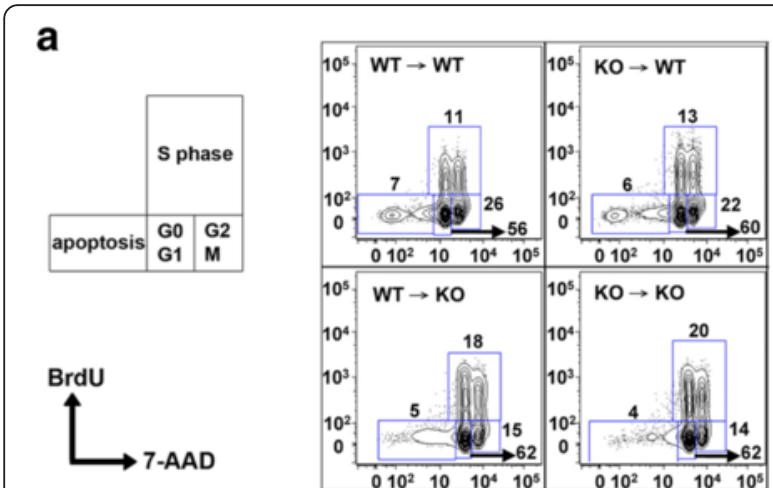

b
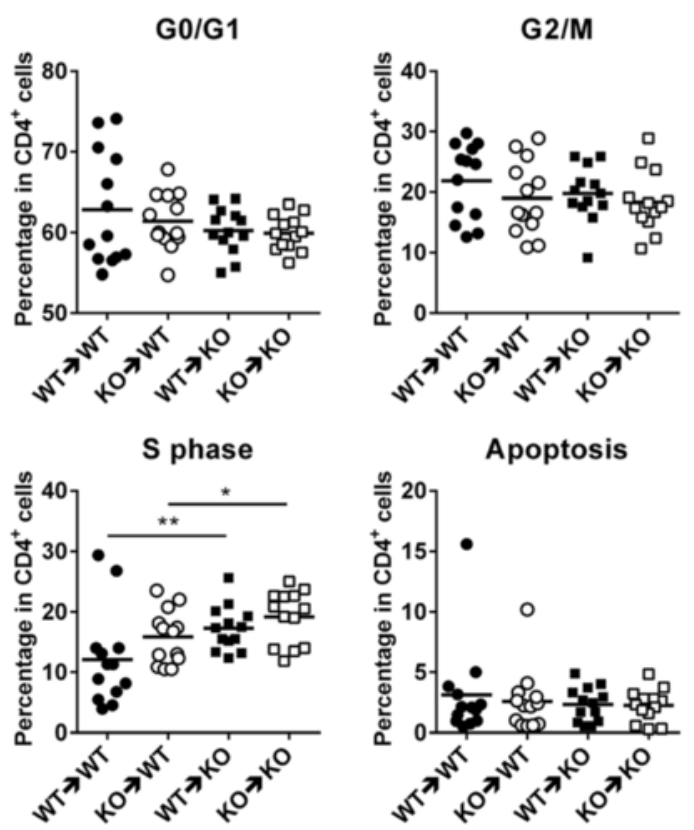

C

$\mathrm{CD4}^{+} \mathrm{IL}-17^{+}$



Fig. 5 The CNS milieu of $\mathrm{CXCR}^{-/-}$mice promotes the proliferation of Th17 cells. Adoptive-transfer EAE was performed as described in Fig. 4. Recipient mice were injected with BrdU on day 11 postimmunization. At 24-h post-injection, the spinal cord was collected and CNS-infiltrating cells were isolated. The cells were immunostained with anti-CD4-APC-Cy7 followed by cell cycle analysis by quantification of cell-incorporated BrdU and total DNA content (7-AAD). a Representative flow cytometry plots for cell cycle analysis. b The percentage of $\mathrm{CD} 4^{+} \mathrm{T}$ cells in the apoptotic phase, G0/G1 phase, $S$ phase, and G2/M phase of the cell cycle among the four groups. c The number of $\mathrm{IL}-17^{+}$cells in $\mathrm{CD}^{+} \mathrm{BrdU}^{+}$(S phase) are shown for the four groups. Each group has 13 mice $(n=13)$. Each mouse is represented by a symbol. Data shown are from two independent experiments. ${ }^{* *} P<0.01 ;{ }^{* * *} P<0.001$

increased compared to WT glial cells, likely owing to an intrinsic effect (Fig. 7). We next examined whether an increase in the number of glial cells in the spinal cord of $\mathrm{CXCR}^{-/-}$mice also contributed to the increased cytokine expression in $\mathrm{CXCR}^{-/-}$mice during EAE. Spinal cord sections from lumbar (Fig. 8a, b) and thoracic regions (Fig. 8c, d) of WT and $\mathrm{CXCR}^{-/-}$mice were subjected to immunofluorescence staining. Astrocytes and microglia were detected using antibodies to GFAP and Iba1, respectively. Astrocytes were not evident within gray matter in naïve $\mathrm{WT}$ or $\mathrm{CXCR}^{-1-}$ mice (data not shown). However, the number of astrocytes $\left(\mathrm{GFAP}^{+}\right)$within gray matter was significantly increased during EAE in both WT and $\mathrm{CXCR}^{-1-}$ mice, but this increase was greater in $\mathrm{CXCR}^{-1-}$ mice (Fig. 8a, c). Notably, astrocytes within white matter in $\mathrm{CXCR}^{-/-}$mice became intensively GFAP immunoreactive (Fig. 8a, c), indicating more severe inflammation in $\mathrm{CXCR}^{-/-}$mice compared with WT mice. These results suggest that astroglial proliferation and hypertrophy in the spinal cord is significantly greater in $\mathrm{CXCR}^{-1-}$ mice than in WT mice. Similarly, microglia within white matter were significantly increased in the spinal cord of $\mathrm{CXCR3}^{-1-}$ mice compared with WT mice (Fig. 8a, c). The increased number of glial cells in the spinal cord of $\mathrm{CXCR}^{-1-}$ mice may also contribute to the increased levels of pro-Th17 cytokines/chemokines, leading to an increase in CNS-infiltrating Th17 cells and thus to the increased EAE severity in $\mathrm{CXCR}^{-1-}$ mice. Notably, the increased number of glial cells in $\mathrm{CXCR}^{-/-}$mice reflected the severity of the inflammation, as evidenced by increased leukocyte infiltration (Fig. 8b, d, upper panel) and demyelination (Fig. 8, d, lower panel) in the spinal cord. Taken together, these results indicate that the increased proTh17 cytokine production observed in the spinal cord of $\mathrm{CXCR}^{-1-}$ mice during EAE results from both the increased number of glial cells in spinal cords (Fig. 8) and the increased pro-Th17 cytokine production per glial cell (Fig. 7). 

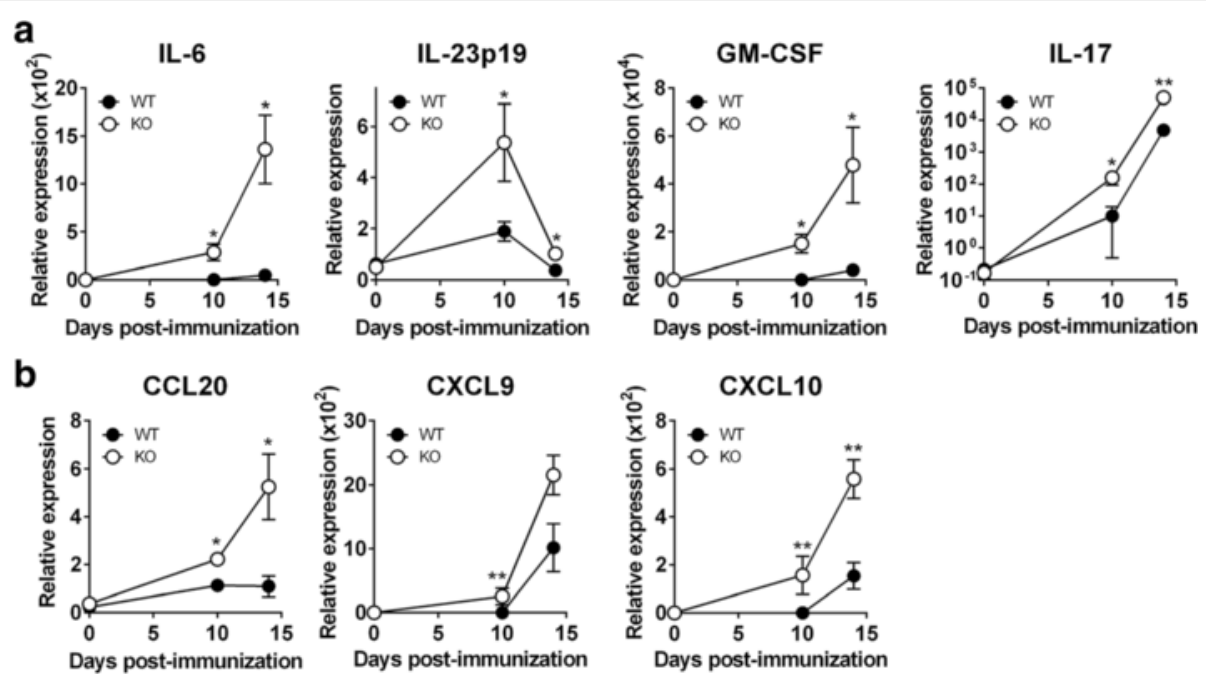

Fig. 6 mRNAs for inflammatory chemokines and cytokines required for Th17 cell expansion are increased in CXCR3 ${ }^{-1-}$ mice during EAE. WT $(n=5)$ and $\mathrm{CXCR}^{-/-}(n=5)$ mice were immunized with MOG. Spinal cords were collected on days 0, 10, and 14 post-immunization, and total RNA was extracted and subjected to real-time PCR analysis to determine the mRNA levels for cytokines (a) and chemokines (b). mRNA levels of target genes, normalized to the level of GAPDH, were analyzed using the $\Delta \Delta \mathrm{Ct}$ method. $n$ stands for the number of mice. ${ }^{*} P<0.05$; ${ }^{* *} P<0.01$

\section{CXCR3 is expressed on glial cells and attenuates NF-KB} activation in glioblastoma cells

Our data showed that CXCR3-deficient glial cells produce increased amounts of cytokines/chemokines compared with WT glial cells (Figs. 6 and 7). We hypothesized that CXCR3 signaling in glial cells might negatively regulate cytokine production. If this was the case, the absence of CXCR3 on glial cells would be predicted to amplify cytokine production. We first examined the expression of CXCR3 on glial cells of the spinal cord during peak of EAE by immunofluorescence staining. Comparing to isotype control antibody for antiCXCR3 shown in Additional file 5: Figure S5, we found that CXCR3 expression was detected on both astrocytes (Fig. 9a) and microglia (Fig. 9b), consisting with previous reports that glial cells express CXCR3 [25-28]. We then investigated whether CXCR3 signaling in glial cells was able to regulate cytokine production negatively using an in vitro experiment with a glioblastoma cell line, U87MG, which expresses CXCR3 (Fig. 10a). It has been shown that CXCR3 signaling induces ERK activation $[37,38]$, that activated ERK attenuates NF- $\mathrm{kB}$ activation [39-41], and that activated $N F-\kappa B$ is required for the transcriptional regulation of $I L-23 p 19$ and CCL2O [42-45]. We hypothesized that CXCR3 signaling might reduce production of IL-23 and CCL20 in glial cells through such a mechanism. Stimulation of U87MG cells with the CXCR3 ligand CXCL10 induced ERK phosphorylation (Fig. 10b), whereas stimulation with IL-17 significantly induced $\mathrm{I} \kappa \mathrm{B}$ phosphorylation (Fig. 10c, lane 1 vs. lane 2). However, IL-17-induced IkB phosphorylation was significantly reduced in cells pretreated with
CXCL10 (Fig. 10c, lane 2 vs. lane 3). Similarly, the nuclear translocation of NF-kB induced by IL-17 stimulation was also significantly reduced in cells pretreated with CXCL10 (Fig. 10d, lane 6 vs. lane 7). Furthermore, pretreatment of cells with PD98059, an ERK inhibitor, completely prevented CXCR3 signaling from attenuating IL-17-induced IkB phosphorylation (Fig. 10c, lane 3 vs. lane 4) and NF-kB activation (Fig. 10d, lane 7 vs. lane 8). To show that attenuated NF- $\mathrm{B}$ activation mediated by CXCR3-signaling-induced ERK was indeed able to reduce CCL20 production, we measured CCL20 secretion in the supernatants of cultured U87MG cells. As expected, the CCL20 secretion induced by IL-17stimulated U87MG cells was also significantly reduced in the presence of CXCL10 (Fig. 10e). These results further confirm that the ERK activation elicited by CXCR3 signaling indeed attenuates NF- $\mathrm{kB}$ activation, leading to a subsequent decrease in CCL20 production. Collectively, these results suggest that CXCR3-expressing glial cells play a role in negatively regulating pro-Th17 cytokine/chemokine production by suppressing NF-kB activation.

\section{Discussion}

Using both active EAE and adoptive-transfer EAE models, we have demonstrated that $\mathrm{CXCR}^{-1-}$ mice exhibit increased infiltrating Th17 cells in the spinal cord, leading to the development of more severe EAE. We have further demonstrated that the increase in CNS-infiltrating Th17 cells in $\mathrm{CXCR}^{-/-}$mice is attributable to the increased number of activated glial cells in the CNS as well as increased levels of pro-Th17 cytokines preferentially 


\section{a Astrocyte}
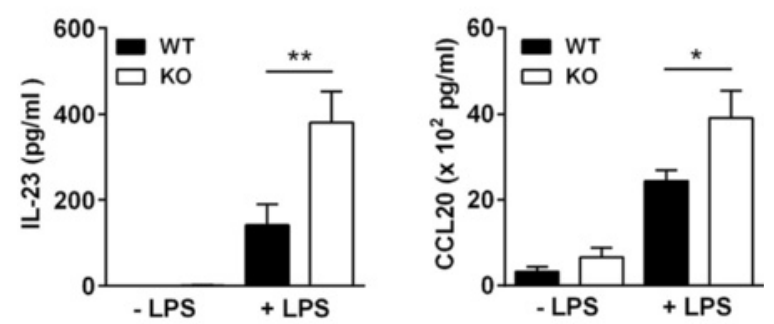

b Microglia
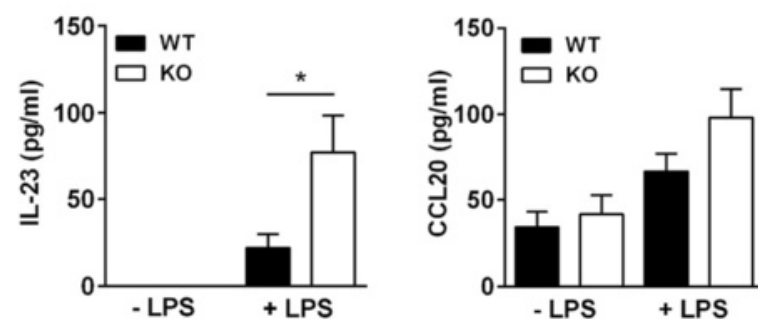

Fig. $7 \mid L-23$ and $C C L 20$ production are significantly increased in glial cells derived from the cortex of neonatal $\mathrm{CXCR}^{-1-}$ mouse brains compared with those from WT mice. The brain cortex was collected from neonatal mice (day 1), and cells were disaggregated. Disaggregated cells were cultured in glial cell enrichment medium for 12 days followed by the separation of astrocytes (a) from microglia (b), as described in the "Methods" section. Astrocytes and microglia were stimulated with LPS for $24 \mathrm{~h}$, and IL-23P19 and CCL20 levels in collected culture supernatants were measured by ELISA. Data represent means \pm SEM from eight independent experiments with three neonatal mice for each experiment. ${ }^{*} P<0.05$; ${ }^{* *} P<0.01$

produced by CXCR3-deficient glial cells. Moreover, we identified suppression of NF- $\mathrm{kB}$ activation by CXCR3 signaling in glial cells as a possible mechanism underlying the negative regulation of pro-Th17 cytokines. Notably, our findings demonstrate a critical role of CXCR3 expressed on glial cells, showing that it prevents the overproduction of Th17 cells by modifying the CNS parenchyma microenvironment so as to limit the expansion and recruitment of Th17 cells during EAE, thus ameliorating disease severity.

CXCR3 and its ligands (CXCL9, CXCL10, CXCL11) are thought to govern the recruitment of leukocytes to the sites of inflammation and infection [15, 46]. One would expect that a deficiency of CXCR3 would reduce the recruitment of effector lymphocytes to the sites of inflammation during EAE, thus conferring resistance to EAE. On the contrary, two previous studies $[29,30]$, together with our current findings, point to $\mathrm{CXCR}^{-1-}$ mice being more susceptible to EAE than WT mice, suggesting that CXCR3 signaling plays a protective role rather than a detrimental role in EAE. Interestingly, although these two previous studies and our study all show the susceptibility of $\mathrm{CXCR}^{-/-}$mice to EAE $[29,30]$, each has proposed a distinct mechanism. It is known that Th17 cells are crucial for EAE pathogenesis [9-12]. Consistent with this notion, we found a significant increase in CNS-infiltrating Th17 cells, but not Th1 cells, in $\mathrm{CXCR}^{-/-}$mice compared with WT mice (Figs. 2 and 4). Given that ligand-bound CXCR3 promotes IFN$\gamma$ production [47] and that the Th1-associated cytokines IFN- $\gamma$ and IL-12 are able to antagonize Th17 cell differentiation and inhibit IL-23-driven proliferation of Th17 cells $[48,49], \mathrm{CXCR}^{-/-}$mice would be expected to have a lower number of Th1 cells and thus fail to efficiently antagonize the proliferation of Th17 cells, leading to an increase in infiltrating Th17 cells in the spinal cord. Interestingly, we did not find a reduction in the number of Th1 cells in CXCR3 $3^{-/-}$mice compared with WT mice; therefore, the increase in CNS-infiltrating Th17 cells in $\mathrm{CXCR}^{-/-}$mice cannot be explained by a reduced number of CNS-infiltrating Th1 cells. Of particular interest, our study demonstrates that the increase in CNS-infiltrating Th17 cells in $\mathrm{CXCR}^{-/-}$mice results from an increase in the number of CNS glial cells, which preferentially generate a cytokine milieu favorable for Th17 cell expansion. Our study is the first to demonstrate the importance of CXCR3 signaling in glial cells during EAE, establishing that CXCR3 expressed on glial cells negatively regulates Th17 cell infiltration into the CNS.

Conflicting results regarding the role of CXCR3 and its ligands in EAE have been reported. Our studies along with others have demonstrated that $\mathrm{CXCR}^{-1-}$ mice are susceptible to EAE [29, 30]. However, results showing resistance to EAE in CXCR3-deficiency mice, or in mice in which CXCR3 was neutralized, have been reported [31-34]. These discrepancies might be due to the species or strain of mice used (rat or B57BL/6 or SJL/J), to the antigens used for immunization (CNS homogenate, MOG, myelin basic protein, or myelin proteolipid protein), to the model used (acute vs. chronic, pharmacologic antagonism, antibody), and to differences in microbiota (co-housing mice, littermate control). Therefore, caution should be exercised in interpreting the data on the role for CXCR3 in EAE; since depending on the model used, CXCR3 signaling may have either pathogenic or regulatory effects. The disparate results from the studies of CXCR3 in EAE are summarized in Additional file 6: Table S1. Studies of the roles for CXCR3 in EAE have been focused on the leukocyte recruitment. However, our study is the first to demonstrate the functional importance of CXCR3 on glial cells negatively regulating Th17 cell expansion during EAE.

Migration of Th17 cells to the CNS has been linked to the induction of inflammation in MS [50] and EAE [9]. The CCR6-CCL20 axis is important for directing Th17 


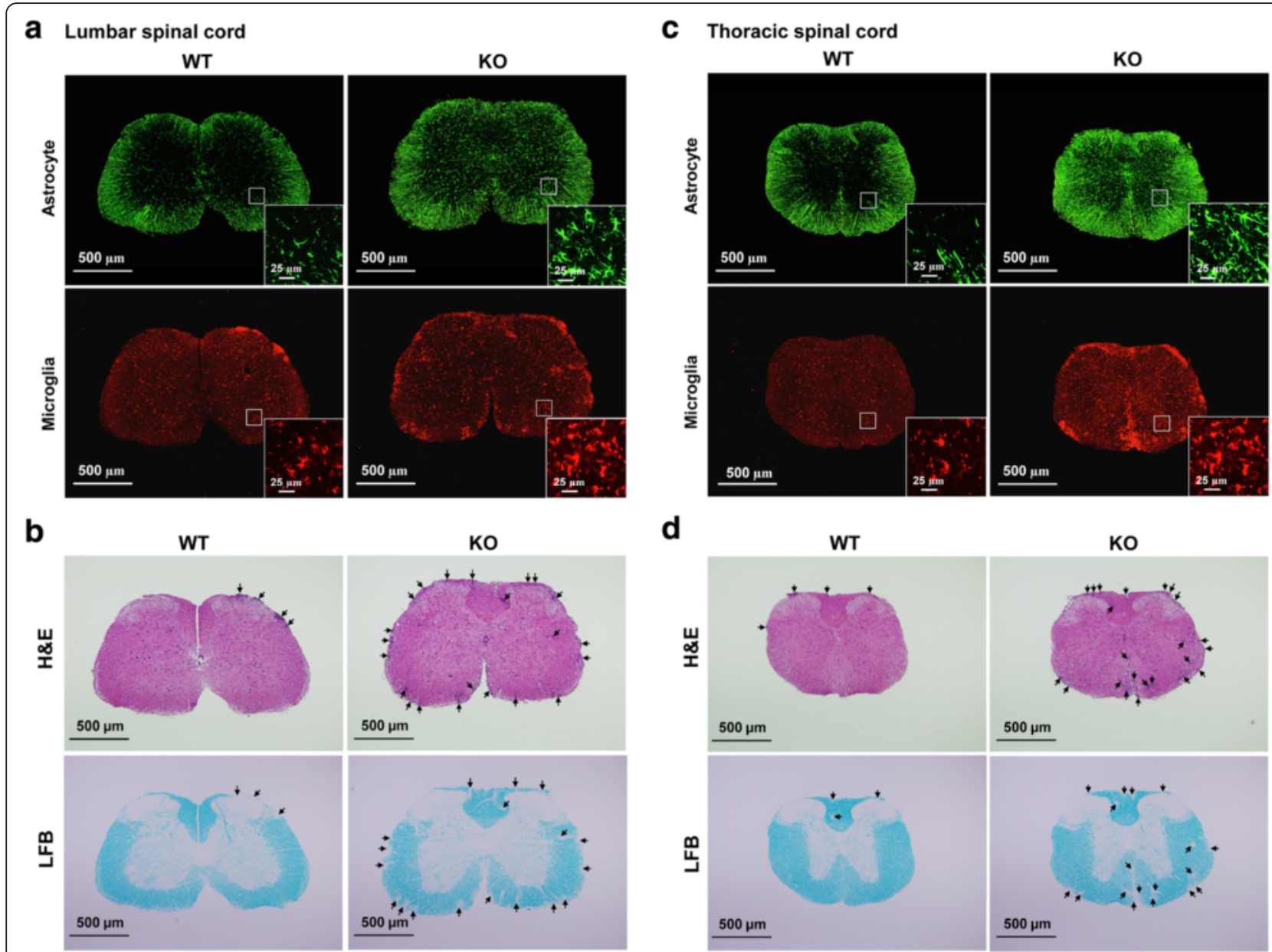

Fig. $8 \mathrm{CXCR}^{-1-}$ mice show elevated numbers of glial cells and increased leukocyte infiltration and demyelination in the spinal cord during EAE. EAE was induced in WT and CXCR3 ${ }^{-1-}$ mice as described in Fig. 1. At 15-days post-immunization, lumbar $(\mathbf{a}, \mathbf{b})$ and thoracic (c, d) spinal cords were collected and subjected to immunofluorescence staining $(\mathbf{a}, \mathbf{c})$ and H\&E as well as LFB staining $(\mathbf{b}, \mathbf{d})$. Immunofluorescence staining for Iba1 (microglial cells) and GFAP (astrocytes) were performed as described in the "Methods" section. Magnified insets highlight the morphology of activated glial cells in lumbar spinal cords (a) or in thoracic spinal cords (c). Infiltrating leukocytes (b, $\mathbf{d}$; upper panel) and demyelination (b, d; lower panel) were detected by H\&E staining and LFB staining, respectively, in lumbar (b) and thoracic (d) spinal cords. Arrows indicate infiltrating leukocytes (b, d; upper panel) and demyelination (b, d; lower panel). Data are representative of three independent experiments

cell migration because Th17 cells preferentially express CCR6, whose ligand is CCL20 [51]. Two recent studies have investigated the mechanism by which Th17 cells enter and/or accumulate in the CNS from peripheral lymphoid organs [12, 52], proposing two different models. Reboldi et al. showed that Th17 cells enter the CNS through the choroid plexus, where CCL20 is highly expressed, and through a CCR6-CCL20-dependent mechanism and migrate into the subarachnoid space of the CNS; there, they are activated/proliferate, triggering the initial inflammation during EAE [12]. Arima et al. reported that the entry site for Th17 cells into the CNS during EAE is at dorsal vessels of the fifth lumber cord, also via the CCR6-CCL20 axis, reflecting the high expression of CCL20 in these vessels [52]. These two studies both implicate the importance of CCR6-CCL20 axis in the initial entry of Th17 cells into the CNS. We found that the levels of CCR6 in Th17 cells polarized from WT CD4 $4^{+} \mathrm{T}$ cells and $\mathrm{CXCR}^{-1-} \mathrm{CD}^{+} \mathrm{T}$ cells were comparable (data not shown); therefore, we anticipate that the initial entry of Th17 cells into the CNS would be comparable between WT and $\mathrm{CXCR}^{-/-}$mice. Following the initial trigger of Th17 cell entry, the infiltrating Th17 cells then further migrate into the CNS parenchyma, where they may undergo further expansion $[12,53,54]$. Given that the CXCR3-deficient spinal cord produces increased levels of cytokines and chemokines favorable for the expansion of Th17 cells compared to the WT spinal cord (Fig. 6) and that Th17 cells in $\mathrm{CXCR}^{-/-}$mice show better expansion than that those 


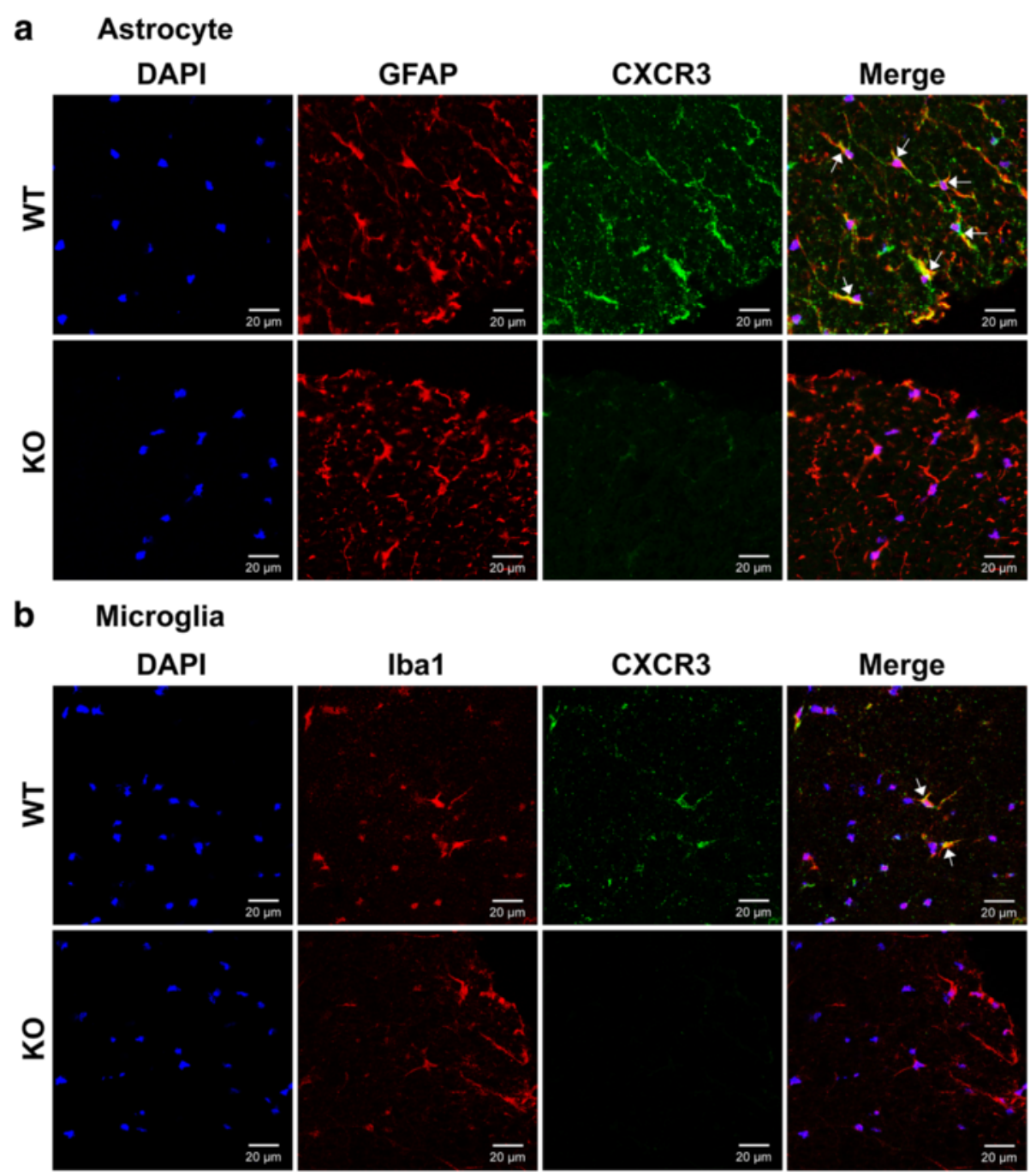

Fig. 9 CXCR3 is expressed on both astrocytes and microglia. Frozen sections of lumbar spinal cord collected from WT and CXCR3 ${ }^{-/-}$mice at the peak of disease (day 15) were subjected to immunofluorescence staining as described in the "Methods" section. a Double-labeling fluorescent staining shows CXCR3 on astrocytes. Anti-CXCR3 (green), anti-GFAP (red), DAPI (blue). b Double-labeling fluorescent staining shows CXCR3 on microglial. Anti-CXCR3 (green), anti-lba1 (red), DAPI (blue). The arrows indicate co-localization of CXCR3 and glial cell markers. The immunofluorescence staining with isotype control antibody for anti-CXCR3 is shown in Additional file 5: Figure S5. Data are representative of three independent experiments

in WT mice (Figs. 4 and 5c), the CXCR3-deficient CNS parenchyma likely generates a favorable microenvironment for Th17 cell expansion. Based on the studies from Reboldi et al. [12] and from Arima et al. [52] together with our study, we propose that the increase in CNSinfiltrating Th17 cells observed in $\mathrm{CXCR}^{-/-}$mice during EAE is attributable to increased Th17 expansion in the CNS parenchyma rather than an increase in the initial entry of Th17 cells into the CNS. Furthermore, CNS-infiltrating Th17 cells are significantly increased in $\mathrm{CXCR}^{-/-}$mice during EAE, likely owing to the increased number of glial cells in the spinal cord of $\mathrm{CXCR3}^{-1-}$ mice (Fig. 8) and to the preferential production of pro-Th17 cytokines in CXCR3-deficient glial cells (Figs. 6 and 7).
Inhibition of NF- $\mathrm{kB}$ in astrocytes has been shown to reduce expression of cytokines and chemokines, resulting in decreased expansion and recruitment of effector leukocytes and subsequent amelioration of EAE [55-57]. $\mathrm{NF}-\mathrm{KB}$ is an essential transcription factor for the induction of both IL-23 [42, 43] and CCL20 [45], which are important for Th17 expansion. Our data showed that CXCR3-deficient glial cells produce more IL-23 and CCL20 than WT glia cells (Fig. 7), suggesting the possibility that CXCR3 signaling negatively regulates proTh17 cytokine production in glial cells. The relevance of this pathway was confirmed by in vitro experiments showing that NF- $\mathrm{BB}$ activation was suppressed by activated ERK elicited by CXCR3 signaling. Consistent with these findings, it has been reported that inhibition of 

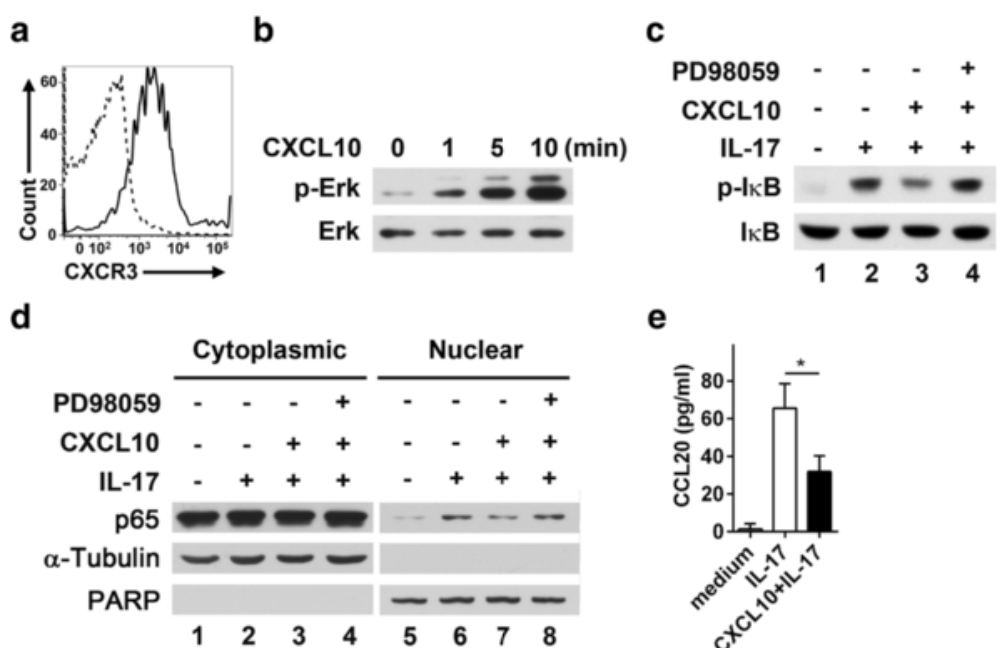

e

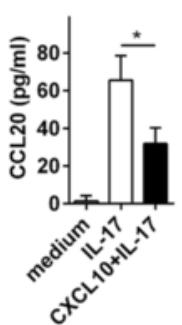

Fig. 10 CXCR3 signaling negatively regulates NF-KB activation induced by IL-17 in a glioblastoma cell line. a U87MG cells were stained with an anti-CXCR3-APC (solid line) or isotype control (dashed line) antibody followed by FACS analysis. b U87MG cells were serum-starved for $6 \mathrm{~h}$ followed by stimulation with CXCL10 $(100 \mathrm{ng} / \mathrm{ml})$. Proteins in whole-cell lysates, prepared at the indicated times, were resolved by SDS-PAGE followed by immunoblotting with anti-p-ERK and anti-ERK antibodies. c U87MG cells were serum-starved for $6 \mathrm{~h}$ and preincubated with or without PD98059 $(10 \mathrm{ng} / \mathrm{ml})$ for $15 \mathrm{~min}$ followed by incubation with CXCL10 (100 ng/ml) for $60 \mathrm{~min}$. Cells were then stimulated with IL-17 (100 ng/ml) for $15 \mathrm{~min}$ followed by cell lysis. Whole-cell lysates were subjected to SDS-PAGE followed by immunoblotting with antibodies to IKB and phospho-IKB. d Similar to $\mathbf{b}$ except that cells were stimulated with IL-17 for $30 \mathrm{~min}$ and cell lysates were fractionated into cytoplasmic and nuclear fractions. Proteins in whole-cell lysates, cytoplasmic fractions, and nuclear fractions were resolved by SDS-PAGE followed by immunoblotting with antibodies to NF-KB p65, $a$-tubulin, and PARP. PARP and $a$-tubulin were used as markers for the nuclear and the cytoplasmic fractions, respectively. e U87MG cells were cultured in complete medium containing IL-17 (100 ng/ml) or IL-17 (100 ng/ml) plus CXCL10 (100 ng/ml) for $48 \mathrm{~h}$, after which CCL20 in culture supernatants was detected by ELISA. Data represent means \pm SEM from four independent experiments. ${ }^{*} P<0.05$

NF-kB in neuroectodermal cells ameliorates EAE $[55,57]$. The detailed molecular mechanism by which CXCR3mediated ERK activity attenuates NF- $\mathrm{kB}$ activation in glial cells warrants further investigation.

EAE and MS are complicated diseases involving both immunological and neurological dysfunctions. The current study provides evidence that CXCR3 in glial cells plays a protective role during EAE, demonstrating that, in addition to its well-known functions in immune cells, CXCR3 on CNS resident cells also plays an important physiological role during EAE.

\section{Conclusions}

This study identifies a protective role of CXCR3 during EAE due to its activity on astrocytes and microglia, adding to the receptor's well-known, more conventional immunologic functions. Our data demonstrate that CXCR3 signaling in glial cells attenuates neuroinflammation during EAE by limiting pro-Th17 cytokine production, thereby restraining Th17 cell expansion, reducing CNSinfiltrating Th17 cells, and subsequently ameliorating EAE. We further provide a possible underlying mechanism in which ERK activation elicited by CXCR3 signaling attenuates the activation of NF- $\mathrm{KB}$ required for the induction of pro-Th17 cytokines.

\section{Additional files}

Additional file 1: Figure S1. $\mathrm{CXCR}^{-/-}$mice have increased mononuclear cells infiltrating in the spinal cord as compared with WT mice. The consecutive sections of the spinal cord (L1) were isolated from MOGimmunized WT and $\mathrm{CXCR3}^{-/-}(\mathrm{KO})$ mice at peak of disease (day 15). LFB staining was performed for detecting demyelinating. The consecutive sections of WT1 to WT12 and KO1 to KO12 were cut rostrally after the sections shown in Fig. 1b. Mononuclear cells infiltrating in white matter were shown as cresyl violet positive cells (purple, original magnification $\times$ 100). (PDF 1986 kb)

Additional file 2: Figure S2. Th17 cells are detected in the spinal cord by immunofluorescence assay. a Frozen sections of the spinal cord from MOG-immunized WT and CXCR3 ${ }^{-/-}$(KO) mice at peak of disease (day 15) were subjected to immunofluorescence staining with rat anti-mouse CD4 / biotin conjugateddonkey anti-rat / Alexa 555-conjugated streptavidin (red) and goat anti-mouse IL-17 / Alexa 488-conjugated donkey anti-goat (green) followed by counterstaining with DAPI (blue). Arrowheads indicate $\mathrm{IL}-17^{+}$cells and arrows indicate $\mathrm{CD} 4^{+} \mathrm{IL}-17^{+}$cells (Th17). b Same procedure in (a) was performed except that goat antimouse IL-17 was replaced by isotype control antibody. (PDF $375 \mathrm{~kb}$ )

Additional file 3: Figure S3. The gating strategy of FACS analysis to identify subpopulations of $\mathrm{CD} 4^{+} \mathrm{IL}-17^{+}$and $\mathrm{CD} 4^{+} \mathrm{IFN}-\gamma^{+}$cells shown in Fig. 4. Mononuclear cells were isolated from the spinal cord of WT and $\mathrm{CXCR3}^{-1-}$ recipient mice at day 12 post-immunization and subjected to FACS analysis. Lymphocytes were gated according to forward and side scatter and then subsequently gated on $\mathrm{CD}^{+}$cells. CD4 ${ }^{+}$cells were further gated to analyze IFN- $\gamma^{+}$cells $\left(\mathrm{CD} 4^{+} \mathrm{IFN}-\gamma^{+}, \mathrm{Th} 1\right)$ and $\mathrm{IL}-17^{+}$cells $\left(\mathrm{CD} 4^{+} \mathrm{IL}-17^{+}, \mathrm{Th} 17\right)$. Data are representative of three independent experiments. (PDF $226 \mathrm{~kb}$ )

Additional file 4: Figure S4. The gating strategy of FACS analysis to identify proliferating Th17 cells shown in Fig. 5. Mononuclear cells were 
isolated from the spinal cord of MOG-immunized WT and CXCR3 ${ }^{-1-}$ recipient mice at day 12 post-immunization and subjected to FACS analysis. Lymphocytes were gated according to forward and side scatter and then subsequently gated on $\mathrm{CD} 4^{+}$cells. $\mathrm{CD} 4^{+}$cells were further gated to analyze cell cycle phase distribution. The phases of the cell cycle of $\mathrm{CD} 4$ cells were indicated (G0/G1: BrdU- 7-AAD ${ }^{+}$G2/M: $\mathrm{BrdU}^{-} 7$ $A A D^{\text {high }}$; S: BrdU $U^{+}$7-AAD high; Apoptosis: BrdU 7-AAD low. ${ }^{-} C^{+} 4^{+}$cells in $S$ phase were further gated to analyze $\mathrm{IL}-17^{+}$cells $\left(\mathrm{CD}^{+} \mathrm{IL}-17^{+}, \mathrm{Th} 17\right)$. Data are representative of two independent experiments. (PDF $183 \mathrm{~kb}$ )

Additional file 5: Figure S5. Isotype control antibody for anti-CXCR3 in Fig. 9. Frozen sections were subjected to immunofluorescence staining as describe in Fig. 9 except that anti-CXCR3 was replaced with isotype control antibody. a Astrocytes were marked as GFAP ${ }^{+}$cells. b Microglia were marked as Ibal ${ }^{+}$cells. GFAP: red, lbal: red, isotype control antibody for anti-CXCR3: green, DAPI: blue. (PDF $981 \mathrm{~kb}$ )

Additional file 6: Table S1. The effect of CXCR3 in various studies. (DOCX $17 \mathrm{~kb})$

\section{Abbreviations}

CNS: central nervous system; EAE: experimental autoimmune encephalomyelitis; ELISA: enzyme-linked immunosorbent assay; FACS: fluorescence-activated cell sorting; MOG: myelin oligodendrocyte glycoprotein; MS: multiple sclerosis; PTX: pertussis toxin; WT: wild-type.

\section{Competing interests}

The authors declare that they have no competing interests.

\section{Authors' contributions}

FL conceived and designed the research study, analyzed the data, and wrote the manuscript. CYC conceived, designed, and conducted the experiments and analyzed the data. Both authors have read and approved the final manuscript.

\section{Acknowledgements}

We are grateful to Dr. Han-Yun Hsiao for helping with the preparation of primary glial cells, to Drs. Chih-Cheng Chen and Cheng-Han Lee for helping with the preparation of the spinal cord staining, Drs. Cathy Fann and HuiMin Wang for helping with the statistical analysis, and Dr. Pauline Yen for the critical reading of the manuscript. This work was supported by grants from Academia Sinica in Taiwan.

\section{Received: 24 November 2015 Accepted: 30 March 2016} Published online: 11 April 2016

\section{References}

1. Sospedra M, Martin R. Immunology of multiple sclerosis. Annu Rev Immunol. 2005;23:683-747.

2. Gold R, Linington $\mathrm{C}$, Lassmann $\mathrm{H}$. Understanding pathogenesis and therapy of multiple sclerosis via animal models: 70 years of merits and culprits in experimental autoimmune encephalomyelitis research. Brain. 2006; 129(Pt 8):1953-71.

3. Leonard JP, Waldburger KE, Goldman SJ. Prevention of experimental autoimmune encephalomyelitis by antibodies against interleukin 12. J Exp Med. 1995;181(1):381-6.

4. Constantinescu CS, Wysocka M, Hilliard B, Ventura ES, Lavi E, Trinchieri G, et al. Antibodies against IL-12 prevent superantigen-induced and spontaneous relapses of experimental autoimmune encephalomyelitis. J Immunol. 1998; 161(9):5097-104

5. Becher B, Durell BG, Noelle RJ. Experimental autoimmune encephalitis and inflammation in the absence of interleukin-12. J Clin Invest. 2002; 110(4):493-7.

6. Oppmann B, Lesley R, Blom B, Timans JC, Xu Y, Hunte B, et al. Novel p19 protein engages IL-12p40 to form a cytokine, IL-23, with biological activities similar as well as distinct from IL-12. Immunity. 2000;13(5):715-25.

7. Cua DJ, Sherlock J, Chen Y, Murphy CA, Joyce B, Seymour B, et al. Interleukin-23 rather than interleukin-12 is the critical cytokine for autoimmune inflammation of the brain. Nature. 2003;421(6924):744-8.

8. Ivanov II, Zhou L, Littman DR. Transcriptional regulation of Th17 cell differentiation. Semin Immunol. 2007;19(6):409-17.
9. Langrish $\mathrm{CL}$, Chen Y, Blumenschein WM, Mattson J, Basham B, Sedgwick JD, et al. IL-23 drives a pathogenic T cell population that induces autoimmune inflammation. J Exp Med. 2005;201(2):233-40.

10. Ivanov II, McKenzie BS, Zhou L, Tadokoro CE, Lepelley A, Lafaille JJ, et al. The orphan nuclear receptor RORgammat directs the differentiation program of proinflammatory IL-17+ T helper cells. Cell. 2006;126(6):1121-33.

11. Komiyama Y, Nakae S, Matsuki T, Nambu A, Ishigame H, Kakuta S, et al. IL-17 plays an important role in the development of experimental autoimmune encephalomyelitis. J Immunol. 2006;177(1):566-73.

12. Reboldi A, Coisne C, Baumjohann D, Benvenuto F, Bottinelli D, Lira S, et al. C-C chemokine receptor 6-regulated entry of $\mathrm{TH}-17$ cells into the CNS through the choroid plexus is required for the initiation of EAE. Nat Immunol. 2009:10(5):514-23.

13. Kebir H, Kreymborg K, Ifergan I, Dodelet-Devillers A, Cayrol R, Bernard M, et al. Human TH17 lymphocytes promote blood-brain barrier disruption and central nervous system inflammation. Nat Med. 2007;13(10):1173-5.

14. Kang Z, Wang C, Zepp J, Wu L, Sun K, Zhao J, et al. Act1 mediates IL-17induced EAE pathogenesis selectively in NG2+ glial cells. Nat Neurosci. 2013:16(10):1401-8.

15. Loetscher M, Gerber B, Loetscher P, Jones SA, Piali L, Clark-Lewis I, et al. Chemokine receptor specific for IP10 and mig: structure, function, and expression in activated T-lymphocytes. J Exp Med. 1996;184(3):963-9.

16. Groom JR, Luster AD. CXCR3 ligands: redundant, collaborative and antagonistic functions. Immunol Cell Biol. 2011;89(2):207-15.

17. Sorensen TL, Trebst C, Kivisakk P, Klaege KL, Majmudar A, Ravid R, et al. Multiple sclerosis: a study of CXCL10 and CXCR3 co-localization in the inflamed central nervous system. J Neuroimmunol. 2002;127(1-2):59-68.

18. Liu L, Callahan MK, Huang D, Ransohoff RM. Chemokine receptor CXCR3: an unexpected enigma. Curr Top Dev Biol. 2005;68:149-81.

19. Liu MT, Chen BP, Oertel P, Buchmeier MJ, Armstrong D, Hamilton TA, et al. The $T$ cell chemoattractant IFN-inducible protein 10 is essential in host defense against viral-induced neurologic disease. J Immunol. 2000; 165(5):2327-30.

20. Stiles LN, Hosking MP, Edwards RA, Strieter RM, Lane TE. Differential roles for CXCR3 in CD4+ and CD8+ T cell trafficking following viral infection of the CNS. Eur J Immunol. 2006:36(3):613-22.

21. Christensen JE, de Lemos C, Moos T, Christensen JP, Thomsen AR. CXCL10 is the key ligand for CXCR3 on CD8+ effector T cells involved in immune surveillance of the lymphocytic choriomeningitis virus-infected central nervous system. J Immunol. 2006;176(7):4235-43.

22. Hsieh MF, Lai SL, Chen JP, Sung JM, Lin YL, Wu-Hsieh BA, et al. Both CXCR3 and CXCL10/IFN-inducible protein 10 are required for resistance to primary infection by dengue virus. J Immunol. 2006;177(3):1855-63.

23. Zhang B, Chan YK, Lu B, Diamond MS, Klein RS. CXCR3 mediates regionspecific antiviral T cell trafficking within the central nervous system during West Nile virus encephalitis. J Immunol. 2008;180(4):2641-9.

24. Marques CP, Kapil P, Hinton DR, Hindinger C, Nutt SL, Ransohoff RM, et al. CXCR3-dependent plasma blast migration to the central nervous system during viral encephalomyelitis. J Virol. 2011;85(13):6136-47.

25. Simpson JE, Newcombe J, Cuzner ML, Woodroofe MN. Expression of the interferon-gamma-inducible chemokines IP-10 and Mig and their receptor, CXCR3, in multiple sclerosis lesions. Neuropathol Appl Neurobiol. 2000:26(2):133-42.

26. Biber K, Dijkstra I, Trebst C, De Groot CJ, Ransohoff RM, Boddeke HW. Functional expression of CXCR3 in cultured mouse and human astrocytes and microglia. Neuroscience. 2002;112(3):487-97.

27. Flynn G, Maru S, Loughlin J, Romero IA, Male D. Regulation of chemokine receptor expression in human microglia and astrocytes. J Neuroimmunol. 2003;136(1-2):84-93.

28. Rappert A, Bechmann I, Pivneva T, Mahlo J, Biber K, Nolte C, et al. CXCR3dependent microglial recruitment is essential for dendrite loss after brain lesion. J Neurosci. 2004;24(39):8500-9.

29. Liu L, Huang D, Matsui M, He T, Hu T, Demartino J, et al. Severe disease, unaltered leukocyte migration, and reduced IFN-gamma production in $\mathrm{CXCR}^{-1-}$ mice with experimental autoimmune encephalomyelitis. J Immunol. 2006:176(7):4399-409.

30. Muller M, Carter SL, Hofer MJ, Manders P, Getts DR, Getts MT, et al. CXCR3 signaling reduces the severity of experimental autoimmune encephalomyelitis by controlling the parenchymal distribution of effector and regulatory T cells in the central nervous system. J Immunol. 2007;179(5):2774-86. 
31. Lalor SJ, Segal BM. Th1-mediated experimental autoimmune encephalomyelitis is CXCR3 independent. Eur J Immunol. 2013;43(11):2866-74.

32. Kohler RE, Comerford I, Townley S, Haylock-Jacobs S, Clark-Lewis I, McColl SR. Antagonism of the chemokine receptors CXCR3 and CXCR4 reduces the pathology of experimental autoimmune encephalomyelitis. Brain Pathol. 2008;18(4):504-16.

33. Sporici R, Issekutz TB. CXCR3 blockade inhibits T-cell migration into the CNS during EAE and prevents development of adoptively transferred, but not actively induced, disease. Eur J Immunol. 2010;40(10):2751-61.

34. Schmitz K, Pickert G, Wijnvoord N, Haussler A, Tegeder I. Dichotomy of CCL21 and CXCR3 in nerve injury-evoked and autoimmunity-evoked hyperalgesia. Brain, Behav Immun. 2013;32:186-200.

35. Hancock WW, Lu B, Gao W, Csizmadia V, Faia K, King JA, et al. Requirement of the chemokine receptor CXCR3 for acute allograft rejection. J Exp Med. 2000;192(10):1515-20.

36. van Weering HR, Boddeke HW, Vinet J, Brouwer $N$, de Haas AH, van Rooijen $\mathrm{N}$, et al. CXCL10/CXCR3 signaling in glia cells differentially affects NMDAinduced cell death in CA and DG neurons of the mouse hippocampus. Hippocampus. 2011;21(2):220-32.

37. Mellado M, Rodriguez-Frade JM, Manes S, Martinez AC. Chemokine signaling and functional responses: the role of receptor dimerization and TK pathway activation. Annu Rev Immunol. 2001;19:397-421.

38. Bonacchi $A$, Romagnani $P$, Romanelli RG, Efsen $E$, Annunziato $F$, Lasagni $L$, et al. Signal transduction by the chemokine receptor CXCR3: activation of Ras/ERK, Src, and phosphatidylinositol 3-kinase/Akt controls cell migration and proliferation in human vascular pericytes. J Biol Chem. 2001;276(13):9945-54.

39. Carter AB, Hunninghake GW. A constitutive active MEK $\rightarrow$ ERK pathway negatively regulates NF-kappa B-dependent gene expression by modulating TATA-binding protein phosphorylation. J Biol Chem. 2000;275(36):27858-64.

40. Yeh PY, Yeh KH, Chuang SE, Song YC, Cheng AL. Suppression of MEK/ERK signaling pathway enhances cisplatin-induced NF-kappaB activation by protein phosphatase 4-mediated NF-kappaB p65 Thr dephosphorylation. J Biol Chem. 2004;279(25):26143-8.

41. Maeng YS, Min JK, Kim JH, Yamagishi A, Mochizuki N, Kwon JY, et al. ERK is an anti-inflammatory signal that suppresses expression of NF-kappaBdependent inflammatory genes by inhibiting IKK activity in endothelial cells. Cell Signal. 2006;18(7):994-1005.

42. Carmody RJ, Ruan Q, Liou HC, Chen YH. Essential roles of c-Rel in TLRinduced IL-23 p19 gene expression in dendritic cells. J Immunol. 2007; 178(1):186-91.

43. Mise-Omata S, Kuroda E, Niikura J, Yamashita U, Obata Y, Doi TS. A proximal kappaB site in the IL-23 p19 promoter is responsible for RelA- and c-Reldependent transcription. J Immunol. 2007;179(10):6596-603.

44. Harant H, Eldershaw SA, Lindley IJ. Human macrophage inflammatory protein-3alpha/CCL20/LARC/Exodus/SCYA20 is transcriptionally upregulated by tumor necrosis factor-alpha via a non-standard NF-kappaB site. FEBS Lett. 2001;509(3):439-45.

45. Sugita S, Kohno T, Yamamoto K, Imaizumi Y, Nakajima H, Ishimaru T, et al. Induction of macrophage-inflammatory protein-3alpha gene expression by TNF-dependent NF-kappaB activation. J Immunol. 2002;168(11):5621-8.

46. Groom JR, Luster AD. CXCR3 in T cell function. Exp Cell Res. 2011;317(5): 620-31.

47. Campbell JD, Gangur V, Simons FE, HayGlass KT. Allergic humans are hyporesponsive to a CXCR3 ligand-mediated Th1 immunity-promoting loop. FASEB J. 2004;18(2):329-31.

48. Harrington LE, Hatton RD, Mangan PR, Turner $H$, Murphy TL, Murphy KM, et al. Interleukin 17-producing CD4+ effector T cells develop via a lineage distinct from the $T$ helper type 1 and 2 lineages. Nat Immunol. 2005; 6(11):1123-32.

49. Park H, Li Z, Yang XO, Chang SH, Nurieva R, Wang YH, et al. A distinct lineage of CD4 $T$ cells regulates tissue inflammation by producing interleukin 17. Nat Immunol. 2005;6(11):1133-41.

50. Tzartos JS, Friese MA, Craner MJ, Palace J, Newcombe J, Esiri MM, et al. Interleukin-17 production in central nervous system-infiltrating $T$ cells and glial cells is associated with active disease in multiple sclerosis. Am J Pathol. 2008;172(1):146-55.

51. Singh SP, Zhang HH, Foley JF, Hedrick MN, Farber JM. Human T cells that are able to produce IL-17 express the chemokine receptor CCR6. J Immunol. 2008;180(1):214-21.
52. Arima Y, Harada M, Kamimura D, Park JH, Kawano F, Yull FE, et al. Regional neural activation defines a gateway for autoreactive $T$ cells to cross the blood-brain barrier. Cell. 2012;148(3):447-57.

53. Axtell RC, Steinman L. Gaining entry to an uninflamed brain. Nat Immunol. 2009;10(5):453-5.

54. Ransohoff RM. Immunology: in the beginning. Nature. 2009;462(7269):41-2.

55. van Loo G, De Lorenzi R, Schmidt H, Huth M, Mildner A, Schmidt-Supprian $M$, et al. Inhibition of transcription factor NF-kappaB in the central nervous system ameliorates autoimmune encephalomyelitis in mice. Nat Immunol. 2006;7(9):954-61.

56. Brambilla R, Persaud T, Hu X, Karmally S, Shestopalov VI, Dvoriantchikova G, et al. Transgenic inhibition of astroglial NF-kappa B improves functional outcome in experimental autoimmune encephalomyelitis by suppressing chronic central nervous system inflammation. J Immunol. 2009;182(5):2628-40.

57. Raasch J, Zeller N, van Loo G, Merkler D, Mildner A, Erny D, et al. IkappaB kinase 2 determines oligodendrocyte loss by non-cell-autonomous activation of NFkappaB in the central nervous system. Brain. 2011;134(Pt 4):1184-98.

\section{Submit your next manuscript to BioMed Central and we will help you at every step:}

- We accept pre-submission inquiries

- Our selector tool helps you to find the most relevant journal

- We provide round the clock customer support

- Convenient online submission

- Thorough peer review

- Inclusion in PubMed and all major indexing services

- Maximum visibility for your research

Submit your manuscript at www.biomedcentral.com/submit
Biomed Central 